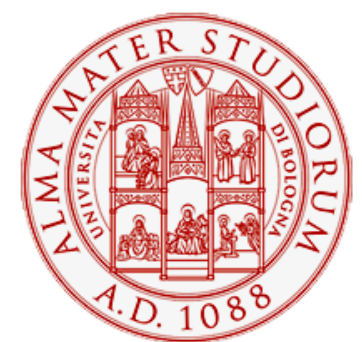

Alma Mater Studiorum - Università di Bologna DEPARTMENT OF ECONOMICS

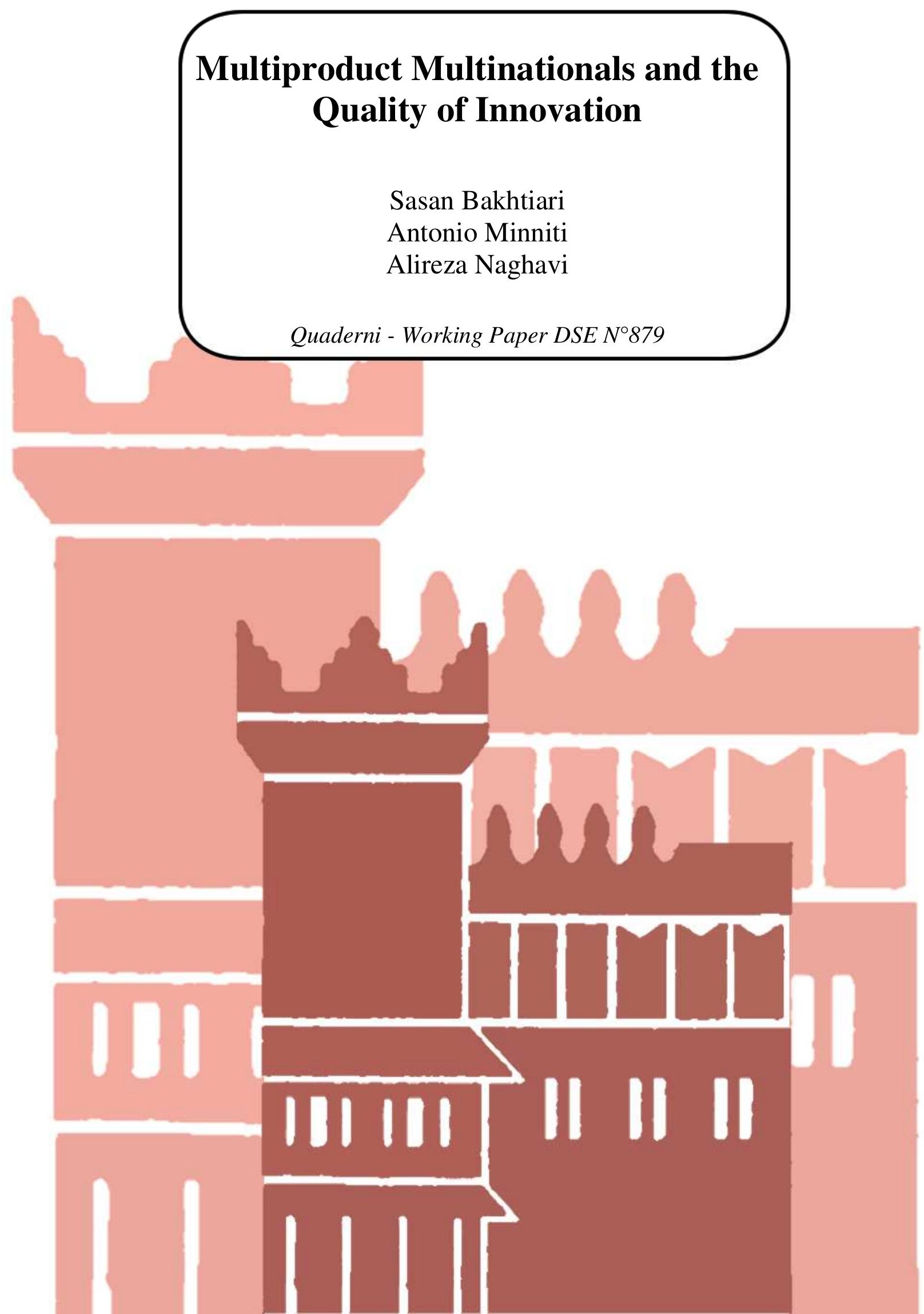




\title{
Multiproduct Multinationals and the Quality of Innovation
}

\author{
Sasan Bakhtiari \\ University of New South Wales
}

\author{
Antonio Minniti \\ University of Bologna
}

\author{
Alireza Naghavi \\ University of Bologna
}

May 7, 2013

\begin{abstract}
This research sheds light on the role of product scope on the innovation activity of multinational multi-product firms. We use patent citation data to break down innovation into two types by measuring the degree to which innovation performed by firms is fundamental and the extent to which the output of the R\&D can be spread across different product lines. We focus on two features in multinational production: (i) fundamental innovation is geographically more difficult to transfer abroad to foreign production sites, (ii) learning spillovers can occur from international operations. The results reveal that the second effect is more likely to dominate when a firm is active in more product lines. We argue that a more diversified portfolio of products increases a firm's scope of learning from international operations, thereby enhancing its ability to engage in more fundamental research. In contrast, firms with less product lines that geographically separate production from innovation shift the innovation activities towards more specialized types of innovation.
\end{abstract}

Keywords: Multinational production, Fundamental innovation, Specialized innovation, Multiproduct firms, Product scope, Knowledge spillovers.

JEL Code: F12, F23, O31, O32.

|

*We are indebted to Peter J. Neary and Gianmarco I.P. Ottaviano for their valuable insights, which guided us in completing this paper. We also thank Ariell Reshef, Francesco Turino, Francesco Venturini, Fabrizio Zilibotti and seminar participants at the University of Bologna and the University of New South Wales for helpful discussions. Of course, all the remaining errors are our own. 


\section{Introduction}

The global fragmentation of production is by now a well-known concept in international trade and is increasingly associated with a strong presence and competitiveness in the world market. While geographically dispersed operation by firms, hereafter referred to as multinational production (MP), is in general accompanied by different forms of cost savings that arise from specialization gains or lower production and transport costs, the evaluation of long-term benefits from this strategy in terms of innovation is not trivial. More specifically, $\mathrm{R} \& \mathrm{D}$ or knowledge spillovers within and across firms tend to play a crucial role in firms' innovation capability and incentives, which are directly affected by the geography of firms' activities.

Evidence regarding the effect of MP on the circulation of knowledge is at best mixed. Jaffe et al. (1993) for instance use patent citation data to provide comprehensive evidence that knowledge spillovers can be geographically localized. Audretsch and Feldman (1996) use US data to argue that the local nature of spillovers could be due to the spacial distribution of production and innovation. This can be caused by imperfect international spillovers that originate from limited feedback from R\&D labs to production sites. Follow up work by Branstetter (2001) and Keller (2002) confirm the limitations on the scope of international knowledge diffusion. At the same time, it is well-documented by now that globally engaged firms are more productive than domestic firms, see for instance Melitz (2003) for exports and Helpman et al. (2004) for FDI. This can originate from channels of learning from the foreign markets (Bernard and Jensen 1999), learning by doing across international affiliates (Brambilla 2009), or feedback from their intra-firm worldwide pool of knowledge or from suppliers, customers, and universities (Criscuolo et al. 2010). These channels all boil down to the question of whether engagement in multinational operations can foster innovation or increase the quality of innovation by firms.

In this research, we consider both the positive and the negative effects of MP on international knowledge spillovers to shed light on the role of product scope in the innovation activity of multinational multi-product firms. The paper contributes to a growing literature in international trade on multiproduct firms by introducing the impact of MP activities and a larger product scope on the quality of innovation performed by firms. The question on how firms alter their product mix according to changes 
in economic conditions in the international market has been addressed by Eckel and Nearv (2010), who show that globalization increases firm productivity but decreases the scope of multi-product firms by shifting their focus towards their core competence. Other influential papers such as Bernard et al. (2011) and Mayer et al. (2012) also provide evidence that tougher international competition leads firms to concentrate on exporting their key products, which in turn enhances their productivity. Our analysis adds to the literature by exploring the endogenous process that causes such improvements in the performance of firms. The idea is to study how being active in several product lines may influence the impact of internationalization on innovation 1

We classify innovation into two types according to how inclusive it is for a firm's overall performance. We refer to "fundamental" as R\&D the output of which can be spread across different product lines. With this we determine the coreness of innovation, as to how much it aims to reduce the core component of the cost function shared among all product lines. We differentiate this from innovation directly related to specific product lines or locations they are intended, which can vary anywhere from incremental to adaptive to organizational innovation. Such a specialized innovation could for instance apply to reducing extra costs associated with introducing more varieties, adapting products to new international markets, or profit maximizing strategies to determine the organization of firm activities. We use patent citation data to determine the fundamental share of firms' innovation activities by applying different indices from Trajtenberg et al. (1997) (and later applied in Rosell and Liu, 2012), namely the generality and the originality of patents. We instead proxy more specialized (less broadly applicable) innovation by using a quantitative measure of the number of patents. We first form a matched firm-patent dataset from two main sources: COMPUSTAT and NBER Patent Citation Data for the years 1985 to 2001. We also make use of the COMPUSTAT segmented data to identify and see how multi-product and international operations are conducive to fundamental patents and innovation.

The results reveal that the product scope of firms plays a decisive role in determining how the geographical fragmentation of production impacts firm incentives to engage in different types of innovation. Our findings are threefold. We first confirm that the negative international knowledge spillover

\footnotetext{
${ }^{1}$ The question of the relationship between innovation, international trade and MP have been elegantly modeled in Atkeson and Burstein (2010) and Arkolakis et al. (2012) respectively. Although the latter does incorporate the geographical separation of innovation and production in the light of Helpman (1984), they do not deal with the role of multi-product firms or spillovers that can arise from the global disintegration of firms' activities.
} 
effect of MP is present and actively reduces fundamental innovation. We then show that the positive learning effect of using various production locations kicks in as a firm engages in more product lines. This allows us to conclude that firms active in multi-segments have a higher scope of learning from international operations and can therefore improve their R\&D activities. Which effect dominates is an empirical question and requires data on the above-mentioned types of innovation. We therefore finally distinguish between fundamental and incremental/adaptive/organizational R\&D to break down firms' innovation activities into those exploitable across all products lines and those that are product specific. We show that firms with a larger share of MP engaged in a larger range of product lines tend to better exploit learning due to the heterogeneous nature of their knowledge and increase their fundamental innovation. In contrast, firms with less product lines that geographically separate production from innovation shift the innovation activities of firms from those directed at its core costs to more specialized types of innovation. This suggests that there is a striking negative correlation between the quality of a firm's research in terms of the fundamental nature of its patents and the quantity of patents it creates.

Our work also bridges the gap between two streams of work in the multi-product literature that deal with multinational production and innovation separately. The concept of multi-product multinationals was first introduced in Baldwin and Ottaviano (2001). Yeaple (2012) has recently expanded the argument to study the simultaneous decisions of firms on the number of products to manage and the mode of serving the foreign market (exports versus MP). He studies the proximity-concentration tradeoff faced by firms in an environment where managerial expertise is in fixed supply within a firm and has to be allocated to particular products and production locations. On the innovation side, Akcigit and Kerr (2012) and Dhingra (2013) study the process (or exploitative) and product (or explorative) innovation by multi-product firms. Both papers argue that access to a larger market through trade does not necessarily translate into the innovation that introduces new products; it increases concentration on process $\mathrm{R} \& \mathrm{D}$ to improve productivity on a narrower range of products. In line with this literature, we provide evidence that incentives for fundamental innovation decreases when firms increase their MP activities per se. We however add to the existing dynamics by showing that an increased scope of learning made possible by multinationalization takes effect when a firm is engaged in more product lines and outweighs the negative effect of the geographical dispersion of production 
on fundamental innovation.

The rest of the paper is as follows. Sections 2 and 3 set up the underlying theory in a closed economy and in the presence of MP respectively. Section 4 provides a description of the data and the respective measures used to characterize innovation. Section 5 delivers our empirical results, while Section 6 concludes by placing the features of our claim in the context of previous conceptual frameworks.

\section{Closed Economy}

We consider a closed economy with $L$ identical consumers, each endowed with a unit of labor. There are two sectors. In the first sector, producers are perfectly competitive and produce a homogeneous good under constant returns to scale with a unit labor requirement. These assumptions imply a unit wage. In the second sector, firms are monopolistically competitive. They pay an entry cost $F$ and produce multiple differentiated products.

\subsection{Consumers}

Agents have identical preferences defined over a continuum of differentiated varieties and a homogeneous good chosen as numéraire. A typical agent consumes $q_{0}$ of the homogeneous good and $q_{j i}$ of variety $i \in \Omega_{j}$ produced by firm $j \in J$. Her utility function is defined as:

$$
U \equiv q_{0}+\alpha \int_{j} \int_{i} q_{j i} d i d j-\frac{\delta}{2} \int_{j} \int_{i} q_{j i}^{2} d i d j-\frac{\eta}{2}\left(\int_{j} \int_{i} q_{j i} d i d j\right)^{2}
$$

where the demand parameters $\alpha, \delta$ and $\eta$ are all positive. As in Melitz and Ottaviano (2008), $\alpha$ and $\eta$ determine substitutability between the homogeneous and differentiated goods: increases in $\alpha$ and decreases in $\eta$ both shift out the demand for the differentiated varieties relative to the numéraire. The parameter $\delta$ measures the degree of product differentiation across varieties. As $\delta$ increases, products become more differentiated. In the limit when $\delta=0$, varieties are perfect substitutes and consumers only care about their consumption level over all varieties, $Q=\int_{j} \int_{i} q_{j i} d i d j$. Assuming that consumers have positive demand for the numéraire good $\left(q_{0}>0\right)$, the inverse demand for firm $j$ 's variety $i$ is then 
given by:

$$
p_{j i}=\alpha-\delta q_{j i}-\eta Q
$$

whenever $q_{j i}>0$. Now, let $\Omega_{j}^{*}$ be the subset of firm $j$ 's varieties that are consumed $\left(q_{j i}>0\right)$. Inverting Eq. (2) yields the linear market demand system for these varieties:

$$
Q_{j i} \equiv L q_{j i}=\frac{\alpha L}{\delta+\eta M}-\frac{L}{\delta} p_{j i}+\frac{\eta M L \bar{p}}{\delta(\delta+\eta M)}
$$

where $Q_{j i}$ denotes the total demand for firm $j$ 's variety $i$ across all agents, $M$ is the measure of varieties consumed in the economy and $\bar{p}=(1 / M) \int_{j} \int_{i} p_{j i} d i d j$ is their average price.

\section{$2.2 \quad$ Firms}

The representative firm $j$ produces $N_{j}$ product varieties. The unit cost of production of each variety presents two components. The first one is common to all product varieties of firm $j$ and is called the "core cost". It amounts to an initial cost $c_{j 0}$ that can be reduced through process innovation $\omega_{j f} \in[0,1]$ and is defined as $c_{j 0}\left(1-\frac{\omega_{j f}^{1 / 2}}{\psi\left(N_{j}\right)}\right)$. We call $\omega_{j f}$ "fundamental innovation". By investing $\omega_{j f}$, firm $j$ is able to reduce the cost of production of all the varieties within its product range. The function $\psi\left(N_{j}\right)$ with $\psi^{\prime}\left(N_{j}\right)>0$ aims to capture the presence of diseconomies of scope in R\&D: as the number of products per firm increases, $R \& D$ becomes less effective at reducing the core cost. The second component amounts to an initial cost $\gamma\left(N_{j}\right)$ that can be reduced through process innovation $\omega_{j i} \in[0,1]$ and is defined as $\gamma\left(N_{j}\right)\left(1-\omega_{j i}^{1 / 2}\right)$. The function $\gamma\left(N_{j}\right)$ has the following properties: (i) $\gamma(0)=0$ and (ii) $\gamma^{\prime}\left(N_{j}\right)>0$. Property (i) implies that this second component of the unit cost is the incremental cost associated with being multi-product. It is equal to zero when firms produce only a single variety $\left(N_{j}=0\right)$. Property (ii), instead, intends to capture the presence of diseconomies of scope in the production of varieties 2 By investing $\omega_{j i}$, firm $j$ is able to reduce the cost of production of the $i$-th variety only. Higher levels of $\omega_{j i}$ correspond to lower levels of variety $i$ 's unit cost and leave unchanged the unit costs of all the other varieties by firm $j$. We call $\omega_{j i}$ "specialized innovation".

\footnotetext{
${ }^{2}$ This can be thought of as the trade-off firms face in Nocke and Yeaple (2012) where managerial expertise can either be used to reduce marginal cost or expand product scope.
} 
Summing the two cost components, the unit cost of production of firm $j$ 's variety $i$ writes as 3

$$
c_{j i}\left(\omega_{j i}, \omega_{j f}\right)=c_{j 0}\left(1-\frac{\omega_{j f}^{1 / 2}}{\psi\left(N_{j}\right)}\right)+\gamma\left(N_{j}\right)\left(1-\omega_{j i}^{1 / 2}\right) .
$$

Firms invest in specialized innovation at a rate $r_{s}$ and in fundamental innovation at a rate $r_{f}$. They also choose how much of each variety to produce. By using (3), the inverse demand for firm $j$ 's variety $i$ writes as:

$$
p_{j i}=a-\frac{\delta}{L} Q_{j i}
$$

where $a \equiv \frac{\alpha \delta}{\delta+\eta M}+\frac{\eta M \bar{p}}{\delta+\eta M}$ summarizes industry demand conditions that firm $j$ takes as given. Firms produce multiple products to amortize their entry costs. We denote by $N_{j}$ the firm $j$ 's product range, which is treated as a continuous variable for mathematical convenience. Firm $j$ decides on its investment in fundamental innovation, $\omega_{j f}$, and in specialized innovation, $\omega_{j i}$, for each product $i$ along with the output of each variety, $Q_{j i}$, to maximize the following profit function:

$$
\max _{Q_{j i}, \omega_{j i}, \omega_{j f}} \Pi_{j}=\int_{0}^{N_{j}}\left[\left(p_{j i}-c_{j i}\right) Q_{j i}-r_{s} \omega_{j i}\right] d i-r_{f} \omega_{j f}-F
$$

With symmetric costs within firms, firm $j$ chooses the same investment in specialized innovation and output for each variety produced, so that we can suppress the firm-product subscripts. Consequently, the profit function (5) can be written as $\Pi=N \pi-r_{f} \omega_{f}-F$ where $\pi$ is profit per product, that is $\pi=\left[p-c\left(\omega, \omega_{f}\right)\right] Q-r_{s} \omega$. In what follows, we derive the first order conditions (FOCs) for the firm problem and determine the optimal $\omega, \omega_{f}$ and $Q$.

\subsubsection{Optimal firm problem}

The FOCs with respect to $\omega, \omega_{f}$ and $Q$ write respectively as:

$$
\frac{\partial \Pi}{\partial \omega}=-c_{\omega}^{\prime}\left(\omega, \omega_{f}\right) Q-r_{s}=0 \Rightarrow \omega=\left[\frac{\gamma(N) Q}{2 r_{s}}\right]^{2},
$$

\footnotetext{
${ }^{3}$ The choice of the exponent $1 / 2$ ensures that the firm's problem is concave. This assumption is not restrictive as this value can be replaced with any positive number less than 1 .
} 


$$
\begin{aligned}
& \frac{\partial \Pi}{\partial \omega_{f}}=-c_{\omega_{f}}^{\prime}\left(\omega, \omega_{f}\right) Q N-r_{f}=0 \Rightarrow \omega_{f}=\left[\frac{c_{0} Q N}{2 r_{f} \psi(N)}\right]^{2} . \\
& \frac{\partial \Pi}{\partial Q}=p-c\left(\omega, \omega_{f}\right)+\frac{\partial p}{\partial Q} Q=0 \Rightarrow Q=\frac{L\left[a-c\left(\omega, \omega_{f}\right)\right]}{2 \delta} .
\end{aligned}
$$

Now, using Eqs. (6) and (7) into Eq. (8) and rearranging terms, we get:

$$
Q=\frac{\left[a-c_{0}-\gamma(N)\right] \frac{L}{2 \delta}}{1-\frac{L}{4 \delta}\left[\frac{\gamma(N)^{2}}{r_{s}}+\frac{N c_{0}^{2}}{r_{f} \psi(N)^{2}}\right]} .
$$

In equilibrium, free entry ensures each firm earns zero profit implying $\Pi=N \pi-r_{f} \omega_{f}-F=0$. Substituting for $\omega$ and $\omega_{f}$ respectively from (6) and (7) into the profit function $\Pi$, the free-entry condition writes as:

$$
\frac{N}{2}\left[a-c_{0}-\gamma(N)\right] Q=F
$$

Using this result into (8), we can easily solve for $Q$ :

$$
Q=\left\{\frac{\frac{L F}{\delta N}}{1-\frac{L}{4 \delta}\left[\frac{\gamma(N)^{2}}{r_{s}}+\frac{N c_{0}^{2}}{r_{f} \psi(N)^{2}}\right]}\right\}^{1 / 2}
$$

Now, plugging $Q$ into (6) and (77), we get the equilibrium levels for $\omega$ and $\omega_{f}$ :

$$
\begin{gathered}
\omega=\frac{\frac{L F \gamma(N)^{2}}{4 \delta N r_{s}^{2}}}{1-\frac{L}{4 \delta}\left[\frac{\gamma(N)^{2}}{r_{s}}+\frac{N c_{0}^{2}}{r_{f} \psi(N)^{2}}\right]}, \\
\omega_{f}=\frac{\frac{L F c_{0}^{2} N}{4 \delta r_{f}^{2} \psi(N)^{2}}}{1-\frac{L}{4 \delta}\left[\frac{\gamma(N)^{2}}{r_{s}}+\frac{N c_{0}^{2}}{r_{f} \psi(N)^{2}}\right]} .
\end{gathered}
$$

\subsubsection{The impact of product scope on the quality of innovation}

To study the impact of product scope on innovation, we first build an indicator for the quality of innovation and, then, we identify the effects of product scope on this index. As a measure of the quality of innovation, we solve for the share of innovation performed by firms that is aimed at reducing 
the core costs relative to that directed at reducing product-specific incremental costs. Using Eqs. (10) and (11), we get:

$$
\text { Quality } \equiv \frac{\omega_{f}}{\omega_{f}+N \omega}=\frac{\frac{c_{0}^{2} N}{r_{f}^{2} \psi(N)^{2}}}{\frac{c_{0}^{2} N}{r_{f}^{2} \psi(N)^{2}}+\frac{\gamma(N)^{2}}{r_{s}^{2}}} .
$$

The product scope affects the Quality index through three different channels. The first one arises from the "diffusive" nature of fundamental innovation: its outcome can be applied broadly to the entire set of firms' varieties. As can be easily seen, $N$ affects directly both the numerator and the denominator of (12) but the net effect of a larger $N$ is positive. This means that a larger product scope increases the Quality index through the first channel. The other two effects arise from the diseconomies of scope (on production and innovation) faced by firms. A larger $N$ increases $\psi(N)$ so that R\&D becomes less effective at reducing the core cost (diseconomies of scope in $\mathrm{R} \& \mathrm{D}) ; \psi(N)$ appears both at the numerator and denominator of (12) but the net effect of a larger product scope is negative. Likewise, a larger $N$ increases $\gamma(N)$ which makes production more costly (diseconomies of scope in the production of varieties). Also this effect is negative on the Quality index. Intuitively, as shown in Eqs. (6) and (7), a larger $\gamma(N)$ increases the investment in specialized innovation $\omega$, whereas a larger $\psi(N)$ increases the investment in fundamental innovation $\omega_{f}$. It follows that a larger product scope decreases the Quality index through these two channels. If the combined effect of the diseconomies of scope dominate the "diffusive" effect of fundamental innovation, then the product scope is likely to have a negative impact on the Quality index. In what follows, we formally analyze the effect of product scope on the quality of innovation. Denoting by $\epsilon_{\psi N}=\frac{\gamma^{\prime}(N)}{\gamma(N)} N$ and $\epsilon_{\gamma N}=\frac{\psi^{\prime}(N)}{\psi(N)} N$ respectively the elasticities of diseconomies of scope in $\mathrm{R} \& \mathrm{D}$ and production with respect to $N$, we can state the following proposition:

Proposition 1. If the diseconomies of scope are sufficiently strong, a higher product scope reduces the quality of innovation. Formally, if $\epsilon_{\psi N}+\epsilon_{\gamma N}>\frac{1}{2}$, then dQuality $/ d N<0$.

Proof. The derivative of (12) with respect to $N$ amounts to:

$$
\frac{d Q u a l i t y}{d N}=\frac{\frac{c_{0}^{2} r_{f}^{2} \psi(N)^{2}-2 r_{f}^{2} \psi(N) \psi^{\prime}(N) c_{0}^{2} N}{\left[r_{f}^{2} \psi(N)^{2}\right]^{2}} \frac{\gamma(N)^{2}}{r_{s}^{2}}-\frac{2 \gamma(N) \gamma^{\prime}(N)}{r_{s}^{2}} \frac{c_{0}^{2} N}{r_{f}^{2} \psi(N)^{2}}}{\left[\frac{c_{0}^{2} N}{r_{f}^{2} \psi(N)^{2}}+\frac{\gamma(N)^{2}}{r_{s}^{2}}\right]^{2}}
$$


This derivative is negative when the numerator is negative. Simplifying, and rearranging terms we easily obtain the condition:

$$
\frac{\psi^{\prime}(N)}{\psi(N)} N+\frac{\gamma^{\prime}(N)}{\gamma(N)} N=\epsilon_{\psi N}+\epsilon_{\gamma N}>\frac{1}{2}
$$

Proposition 1 provides the condition under which a larger product scope results in a lower quality of innovation. Namely, if the sum of the elasticities of diseconomies of scope with respect to $N$ are sufficiently large, a greater product scope reduces the quality of innovation. For instance, the situation holds when each of the functions $\psi(N)$ and $\gamma(N)$ is increasing at least as fast as $N^{1 / 4}$. Recall that the diseconomy of scope in $R \& D$ reduces fundamental innovation, while the diseconomy of scope in the production of varieties increases specialized innovation, they therefore both contribute to a negative effect of $N$ on the Quality index. The extent of the diseconomies of scope and whether or not they dominate the positive diffusive channel of fundamental innovation remains an empirical question, which will be addressed in our econometric exercise.

\section{Multinational Production}

We now move to an open economy, where firms can produce a fraction $S$ of their output overseas. Demand continues to be determined by $L$ identical consumers in the world market, which also determine the total mass of labor. The problem of firms remains as in the previous section with two additional components: limited international transferability of firm's fundamental $R \& D$ and learning spillovers from operating in international markets. We refer to the former as the negative and the latter as the positive externalities of MP.

As described in the Introduction, evidence points towards the localized nature of firms' fundamental R\&D. Using this argument, we presume that fundamental R\&D is more likely to remain in firms' headquarters, while specialized R\&D can more easily follow a specific product to the location of its production. We therefore implement that a proportion $\phi$ of fundamental innovation is lost when 
applied in the international sites of a multinational. Consequently, a firm can only realize a reduction in its core cost equivalent to a fraction $1-\phi S$ of the fundamental innovation it undertakes. In the following analysis, we denote by $\phi S$ the total loss from limited international spillovers.

A series of recent evidence points out the important role of geographical and product space in determining the extent of within- and cross-firm knowledge spillovers, see Lychagin et al. (2010) and Bloom et al. (2013). Operation in international markets can therefore be associated with learning spillovers, whereas diversified knowledge within a firm can influence the scope of learning from other firms (or markets). In our model, this is captured by multinationals active in more diverse product lines being better posed to exploit such learning spillovers. We model learning externalities as the functional relationship $\theta \equiv \theta(N, S)$, where the following properties hold: (i) $\theta(N, 0)=0$, (ii) $\theta_{S}^{\prime}(N, S)>0$, and (iii) $\theta_{N}^{\prime}(N, S)>0$. Properties (i) and (ii) come from the definition of learning spillovers from international markets, and property (iii) implies that firms with activities in more segments can learn and absorb from a larger scope of overseas knowledge. As we are mostly concerned with studying the negative and positive externalities of MP on fundamental innovation, we assume that learning is most relevant for the more fundamental component of innovation and that more customized (or less qualitative) innovation is neither affected by the negative nor the positive effect of international operations on knowledge spillovers. Consequently, a firm can enhance the impact of its fundamental innovation by engaging in MP with a factor of $1+\theta(N, S)$.

With the added components just discussed above, the unit cost function for firm $j$ in the presence of MP can be rewritten as follows:

$$
c_{j i}\left(\omega_{j i}, \omega_{j f}\right)=c_{j 0}\left[1-\left(1+\theta\left(N_{j}, S\right)\right) \frac{\omega_{j f}^{1 / 2}(1-\phi S)}{\psi\left(N_{j}\right)}\right]+\gamma\left(N_{j}\right)\left(1-\omega_{j i}^{1 / 2}\right) .
$$

Eqs. (13) highlights that MP can on the one hand block perfect spillovers of fundamental R\&D to a firm's foreign production locations and on the other hand enhance fundamental innovation through learning spillovers from foreign markets. 


\subsection{Optimal firm problem in the presence of MP}

Taking the FOCs with respect to $\omega, \omega_{f}$ and $Q$ as in Eqs. (66)-(8) and solving for free entry under zero profits yields $Q$ in the presence of MP and symmetry across firms:

$$
Q=\left\{\frac{\frac{L F}{\delta N}}{1-\frac{L}{4 \delta}\left[\frac{\gamma(N)^{2}}{r_{s}}+\frac{N c_{0}^{2}}{r_{f} \psi(N)^{2}}(1+\theta(h, S))^{2}(1-\phi S)^{2}\right]}\right\}^{1 / 2} .
$$

We can next obtain the equilibrium levels for $\omega$ and $\omega_{f}$ when MP is a possibility:

$$
\begin{gathered}
\omega=\frac{\frac{L F \gamma(N)^{2}}{4 \delta N r_{s}^{2}}}{1-\frac{L}{4 \delta}\left[\frac{\gamma(N)^{2}}{r_{s}}+\frac{N c_{0}^{2}}{r_{f} \psi(N)^{2}}(1+\theta(N, S))^{2}(1-\phi S)^{2}\right]}, \\
\omega_{f}=\frac{\frac{L F c_{0}^{2} N}{4 \delta r_{f}^{2} \psi(N)^{2}}(1+\theta(N, S))^{2}(1-\phi S)^{2}}{1-\frac{L}{4 \delta}\left[\frac{\gamma(N)^{2}}{r_{s}}+\frac{N c_{0}^{2}}{r_{f} \psi(N)^{2}}(1+\theta(N, S))^{2}(1-\phi S)^{2}\right]} .
\end{gathered}
$$

\subsection{The impact of MP on the quality of innovation}

We now proceed to solve for the quality of innovation performed by firms and see how it can be influenced by MP. As before, to characterize the quality of innovation, we solve for the share of innovation performed by firms that is aimed at reducing the core costs relative to that directed at reducing product-specific incremental costs. Using Eqs. (14) and (15), this can be calculated as:

$$
\text { Quality } \equiv \frac{\omega_{f}}{\omega_{f}+N \omega}=\frac{\frac{c_{0}^{2} N}{r_{f}^{2} \psi(N)^{2}}(1+\theta(N, S))^{2}(1-\phi S)^{2}}{\frac{c_{0}^{2} N}{r_{f}^{2} \psi(N)^{2}}(1+\theta(N, S))^{2}(1-\phi S)^{2}+\frac{\gamma(N)^{2}}{r_{s}^{2}}}
$$

Changing the share of output that is produced overseas by firms produces two effects on the Quality index. The first effect is positive and arises from learning spillovers: increasing the share of operation in international markets $S$ makes the scope of learning from other firms $\theta(N, S)$ larger. As a result, R\&D becomes more effective at reducing the core cost. Because a larger $S$ increases the investment in fundamental innovation $\omega_{f}$, it also increases the Quality index. The second effect is negative and is due to the localized nature of firms' fundamental R\&D: increasing the share of output that 
is produced overseas $S$ makes the loss from being multinational $\phi S$ larger. Consequently, in this case, $\mathrm{R} \& \mathrm{D}$ becomes less effective at reducing the core cost. We conclude that a larger $S$ decreases the investment in fundamental innovation $\omega_{f}$ and the Quality index through this second effect. For the next proposition let $\theta(N, S)$ be multiplicative separable, that is $\theta(N, S)=\theta_{1}(N) \theta_{2}(S)$, for the tractability of results. Denoting by $\epsilon_{\theta S}=\frac{\theta_{S}^{\prime}(N, S)}{\theta(N, S)} S$ the elasticity of $\theta(N, S)$ with respect to $S$, we can state the following proposition:

Proposition 2. When learning spillovers from MP activities are sufficiently large, formally $\epsilon_{\theta S}>$ $\frac{\phi S}{(1-\phi S)}$, there exists a threshold product scope above (below) which MP increases (decreases) the quality of innovation.

Proof. The derivative of (16) with respect to $S$ is:

$$
\frac{d Q u a l i t y}{d S}=\frac{\frac{2 c_{0}^{2} N}{r_{f}^{2} \psi(N)^{2}}\left[(1+\theta(N, S))(1-\phi S)^{2} \theta_{S}^{\prime}(N, S)-(1+\theta(N, S))^{2}(1-\phi S) \phi\right] \frac{\gamma(N)^{2}}{r_{s}^{2}}}{\left[\frac{c_{0}^{2} N}{r_{f}^{2} \psi(N)^{2}}(1+\theta(N, S))^{2}(1-\phi S)^{2}+\frac{\gamma(N)^{2}}{r_{s}^{2}}\right]^{2}} .
$$

The sign of the above derivative is determined by the expression

$$
(1-\phi S) \theta_{S}^{\prime}(N, S)-(1+\theta(N, S)) \phi \lessgtr 0 .
$$

Using $\theta(N, S)=\theta_{1}(N) \theta_{2}(S)$, the expression can be written as

$$
\theta_{1}(N) \lessgtr \frac{\phi}{(1-\phi S) \theta_{2}^{\prime}(S)-\phi \theta_{2}(S)} .
$$

When the elasticity of learning spillovers with respect to $S$ is large enough so that $\epsilon_{\theta S}>\frac{\phi S}{(1-\phi S)}$, the denominator in (17) is positive. Fixing $S$, and by the monotonicity of $\theta_{1}(N)$, there exists a threshold $N^{*}(S)$ such that for $N<N^{*}(S)$ the derivative is negative and for $N>N^{*}(S)$ the derivative turns positive.

To elucidate the role of the product range in shaping the relationship between the quality of innovation and the share of MP activities, consider a simplified case when $\theta(N, S)=N S$. Plugging 
this function back into (17) generates a closed form condition:

Corollary 1. When $\theta(N, S)=N S$, then

$$
N^{*}(S) \lessgtr \frac{\phi}{1-2 \phi S},
$$

determines the threshold level of product scope that reverses the negative impact of MP operation on the quality of innovation.

Proposition 2, along with Corollary 1, establishes that a higher loss from limited international spillovers, $\phi S$, makes it more likely for MP to cause a reduction in the quality of innovation. The condition $\phi S>1 / 2$ in Corollary 1 specifically outlines the level of losses that makes this effect always prevail. The proposition further establishes that the product range plays an important role in the relationship between the quality of innovation and the share of MP. The benefit from learning spillovers is increasing in the number of business segments in which the firm operates. Thus, it is more likely that the positive learning effect of MP prevails over the negative effect when the number of products gets larger. We therefore expect the interaction term between MP and the number of business segments to be positive. This highlights the positive role that a larger number of products can play in increasing fundamental innovation regardless of the negative forces it creates through diseconomies of scope. We shed light on this issue below by first illustrating the relationship between MP and the quality of innovation through a numerical example. We then proceed with our empirical investigation.

\subsection{An example}

Suppose that the diseconomies of scope take a specific functional form that is increasing in $N$ :

$$
\psi(N)=1+N
$$

Note that $\psi(0)=1$ and is linearly increasing in $N$. This gives the positive diffusion effect of more products a concave shape. In other words, the benefits from fundamental innovation are decreasing in 
$N$ as the function $\frac{N}{\psi(N)}=\frac{N}{1+N}$ is concave 4 Incremental costs of introducing new products are also increasing in $N$ inducing more specialized innovation. This also works as a negative force towards the share of investments dedicated to fundamental innovation. To capture this, we give a simple functional form to $\gamma(N)$ that is linear in $N$ (with $\gamma(0)=0$ ) that is:

$$
\gamma(N)=N
$$

Equation (16) hence turns to:

$$
\text { Quality } \equiv \frac{\omega_{f}}{\omega_{f}+N \omega}=\frac{\frac{c_{0}^{2}}{r_{f}^{2}} \frac{N}{(1+N)^{2}}(1+S N)^{2}(1-\phi S)^{2}}{\frac{c_{0}^{2}}{r_{f}^{2}} \frac{N}{(1+N)^{2}}(1+S N)^{2}(1-\phi S)^{2}+\frac{N^{2}}{r_{s}^{2}}}
$$

We further give values $c_{0}=0.9, r_{f}=0.2, r_{s}=0.2$ and $\phi=0.5$ without loss of generality. Figure 1 depicts the effect of MP on the quality of innovation for different levels of product scope $N=0.5$, $N=1$ and $N=2$. It is easy to see that when the product scope is small, a higher fraction of MP reduces the quality of innovation. Increasing the product scope to $N=1$, we see the positive learning spillovers taking effect for low values of $S$ creating an inverted-U shaped relationship between the quality of innovation and $S$. Finally, for sufficiently large values of product scope such as $N=2$, MP is always increasing the quality of innovation, except for very large values of $S$. It will be seen in the empirical section that the maximum value of $S$ in our data is low. The effect of MP on the quality of innovation is therefore unambiguously positive in the lower region of $S: 5$

\footnotetext{
${ }^{4}$ The linear form of $\psi(N)$ is not restrictive. Similar results also obtain for other functional forms of $\psi(N)$. Take for example a more drastic form of diseconomies of scope that is convex in $N$. This gives $\psi(N)=\left(1+N^{2}\right)$ so that $\frac{N}{\psi(N)}=\frac{N}{1+N^{2}}$. The benefits from $N$ continue to be concave, but transform to losses when $N>1$. However, this does not make any qualitative changes to our analysis.

5 The interaction between MP and product scope can also be expressed the other way around by seeing how a change in $S$ influences the impact of $N$. We observe from the derivative of (18) with respect to $N$ that the quality of innovation is decreasing in $N$ as long as $\left(N^{3} S^{2}+3 N^{2} S^{2}+4 N S-N+1\right)<0$. When $S=0$, it is decreasing in $N$ as long as $N>1$, but the negative impact is decreasing (and less likely to dominate) as $S$ rises.
} 


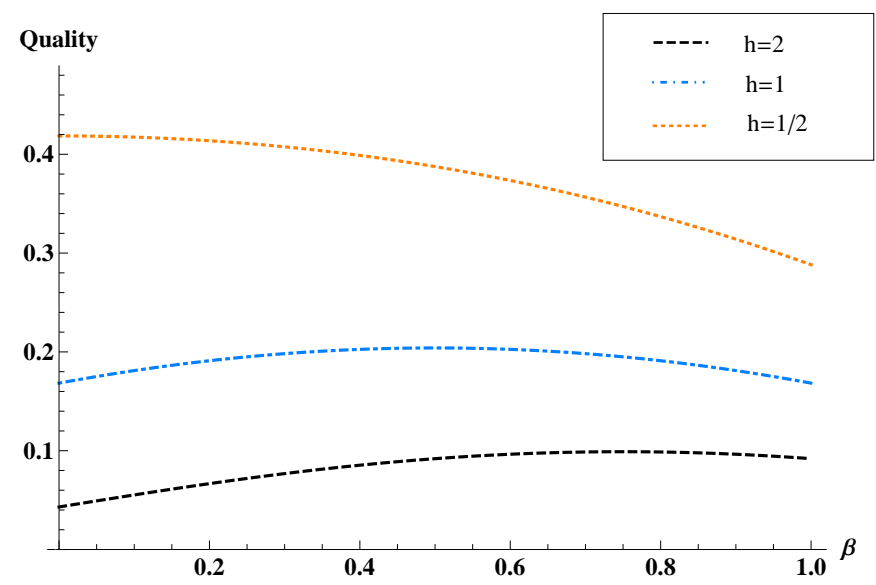

Figure 1: The relationship between the quality of innovation and MP

\section{Data}

To lead our empirical study, we form a matched firm-patent dataset from two main sources: COMPUSTAT and NBER Patent Citation Data. The source of our firm-level data is COMPUSTAT annual fundamentals that report a rich set of economic and financial information on the publicly traded firms in the U.S. over the years 1964 to (currently) 20106 For our exercises, we especially make use of the following set of information:

- employment size $(E M P)$,

- annual sales $(S A L E)$,

- annual R\&D expenditures $(X R D)$,

- and annual advertising expenditures $(X A D)$.

To focus on products and innovation in the conventional sense, we restrict ourselves to those firms in COMPUSTAT that report their main activity as manufacturing (SIC 2xxx and 3xxx). However, we drop manufacturing sector 21xx (Tobacco products) because it is a small group of very large firms with

\footnotetext{
${ }^{6}$ Made available by Wharton Research Data Services at http://wrds-web.wharton.upenn.edu/wrds/
} 
very little within industry variations. To make the direction of trade clear, we also restrict ourselves to firms that are headquartered in the U.S. (FIC="USA").

In building those factors that impact innovation, we need to account for a firm's stock of R\&D as a representation of the firm's knowledge capital at the time of innovation. Following Hall (1990), we construct the R\&D stock in a firm using the following perpetual inventory model:

$$
R_{t+1}=(1-\delta) R_{t}+X R D_{t+1}
$$

in which, $\delta=0.15$. For the first year of a firm, we compose the R\&D stock using the proposition by Hall (1990) to write $R_{0}=X R D_{0} /(\delta+0.08)$. Since our investigation is centered around the concept of quality of innovation, the stock of a firm's commercial advertisement is one signal that the firm intends to engage in more specialized and commercial innovations. We would have constructed a firm's stock of advertisement using a perpetual inventory model as above, however, the findings of Clarke (1976) suggest that the effective lifespan of advertising expenditures is less than a year (a 100\% annual depreciation rate). As a result, $X A D$ by itself suffices as the stock of advertisement. The values of $S A L E, X R D$ and $X A D$ are turned into real terms before usage by applying the shipment deflators reported in NBER Manufacturing Database to compensate for price differences across manufacturing subsectors as well as inflation (Bartelsman and Gray, 1996).

We further supplement our firm-level data with the set of new patents applied for by the firm during each year. The patent information are fetched from the NBER Patent Citation Data that list granted patents from 1901 to 2006 and the citations of patents granted from 1976 to 2006. Some available information for each patent is the USPTO classification code, the application and granting years, and the citations made to preceding patents. Hall et al. (2001) add to the patent database their own technology code, which has a better hierarchical structure but is less detailed than the USPTO classification codes. Patents are matched to the firm level data by firms' assigned identification code $(G V K E Y)$ with the links provided by the file dynass.dta in the patent dataset. For this application, we regard the year of patent application as the year of innovation. In doing so, we are following the lead by Hall et al. (2001) where they document that there is on average a two-year gap (with some 
variation) between the year a patent is applied for and the year the patent is actually granted.

We also make use of the COMPUSTAT segmented data to identify multi-product and international operations. One set of information provided in the data pertains to business segments, with business segments indicating a firm's operation in distinct 4-digit SIC areas (reported for most segments, but missing for a small number of firms). The data coverage is more limited than the annual file and only spans 1976 to (currently) 2010. Given the level of industry specification in the segmented file, our definition of products is broader than traditionally used in the literature. But, we believe that such broad description of products, as opposed to the narrower 7-digit SIC, is advantageous to our investigations. The reason is that we are looking at the applicability of patents (or innovations) to various different fields, and we need to make a certain degree of distinction between products to see the real diversity of applications. For instance, in the manufacturing of glass containers (SIC 3221), a patent can be easily applied to the subgroups of glass bottles, carboys, fruit jars, etc. with minor adaptations. It takes innovations of higher fundamental nature to apply the same patent to both glass bottles (SIC 3221) and pressed and blown glassware (SIC 3229), the latter pertaining to a range of products including (but not limited to) glass artworks, dishes, lanterns, and trays.

Our first measure for the number of products is simply the count of 4-digit business segments for each firm in a certain year $(N 4)$. However, this count is crude and does not especially take into account how distant and diverse products in a firm are. It is useful to make distinction between a twoproduct firm that produces glass bottles (SIC 3221) and glassware (SIC 3229) and another two-product company that produces glass bottles (SIC 3221) and plastic bottles (SIC 2821). We are hypothesizing that the latter firm would require a larger investment in fundamental research to reduce the costs of its two products. Our first adjusted measure for the number of products simply aggregates business segments to 3-digit SIC and counting the number of products (N3). In this way, multi-product firms are those with more diverse products. Our last measure is to adjust $N 4$ to reflect this diversity. For this purpose, we first form a Herfindal index of how diverse the product lines are at 3-digit SIC. Formally, we set

$$
H=1-\sum_{n=1}^{N 3}\left(\frac{\#(\text { Same } 3 \text {-digit SIC })_{n}}{N 4}\right)^{2}
$$


In the index above, the term in parentheses is the share of 4-digit SIC segments that fall into the same 3-digit SIC segment. Then, the adjusted number of products is

$$
N H=N 4 \times H+1 .
$$

When $H=0$ (no diversity at 3-digit level), then $N H=1$, that is, the firm is producing products that are close enough to qualify as only one product. With perfectly even distribution of products among different 3-digit product lines, $H=1-1 / N 4$ and $N H=N 4$; products are so diverse that each one counts as a distinct line.

In addition to business segments, firms separately report their sales by geographic segments. Each geographic segment describes the operation of the firm in a distinct geographic location (country is the minimum level of distinction). One obvious geographic segment is the U.S. division, especially since we are only focusing on those firms headquartered in the U.S. Firms are very inconsistent in reporting the details of their overseas operation: some firms only report their total overseas sales, some others report it by the continent of operation, and a few firms report sales by each foreign country. To bypass these inconsistencies, we only focus on international versus domestic operations of firms. At the end, we have the share of international operation for each firm that is

$$
S=1-\frac{\text { Annual Sales of the U.S. segment }}{\text { Total Annual Sales }}
$$

Table 1 lists the composition of our analysis sample by year. For the feasibility of the empirical strategy that we will describe in the next section, we restrict ourselves to the years 1985 to 2001 (total of 16 years) and only keep firms that have been in our data for at least three pre-sample periods and also the first 10 years of our sample. These restrictions leave us with about 1,100 firms in the first ten years, while our sample is still unbalanced for the remaining years with a declining number of firms. These firms applied for more than 10,000 patents a year. In the beginning years of our sample, about one-third of firms are multi-product $(N 4>1)$ and around half of firms have some international operation $(S>0)$. 


\begin{tabular}{|c|c|c|c|c|}
\hline Year & \# Firms & \#Patents & $\begin{array}{l}\text { \#Multi- } \\
\text { product }\end{array}$ & $\begin{array}{l}\text { \#Off- } \\
\text { shoring }\end{array}$ \\
\hline 1985 & 1,116 & 11,593 & 276 & 510 \\
\hline 1986 & 1,116 & 11,803 & 295 & 509 \\
\hline 1987 & 1,116 & 12,529 & 296 & 495 \\
\hline 1988 & 1,116 & 13,837 & 305 & 497 \\
\hline 1989 & 1,116 & 15,028 & 311 & 475 \\
\hline 1990 & 1,116 & 15,671 & 320 & 474 \\
\hline 1991 & 1,116 & 15,811 & 328 & 472 \\
\hline 1992 & 1,116 & 16,316 & 333 & 466 \\
\hline 1993 & 1,116 & 16,979 & 342 & 460 \\
\hline 1994 & 1,116 & 18,174 & 356 & 456 \\
\hline 1995 & 1,052 & 20,503 & 344 & 427 \\
\hline 1996 & 1000 & 19,028 & 328 & 407 \\
\hline 1997 & 919 & 16,230 & 307 & 363 \\
\hline 1998 & 708 & 13,086 & 185 & 278 \\
\hline 1999 & 528 & 11,803 & 194 & 272 \\
\hline 2000 & 453 & 10,772 & 195 & 280 \\
\hline 2001 & 407 & 9,855 & 186 & 272 \\
\hline
\end{tabular}

Table 1: The count of firms and patents by year. Multi-product are firm with more than one product line $(N 4>1)$. Offshoring are firm with non-zero share of international operation $(S>0)$.

The distribution of firms by the number of products and also by their share of international production is, however, very skewed. Figure 2 shows the distributions by pooling all firm-years. About $90 \%$ of firm-years in our data have less than four products, while less than $0.4 \%$ of firm-years have seven products or more. Similarly, about $95 \%$ of firms in our data have less than half of their operation in foreign countries, while less than $0.3 \%$ are almost fully operating overseas with only headquarters in the U.S.

\subsection{Measuring Fundamental Innovation}

In the popular literature, there has not been one standard definition for the quality of a patent and whether the patent falls into a fundamental category by our earlier definition. We use a multitude of measures that have some correlation with our notion of fundamental innovation and use them to robustly test our hypothesis. These measures are the standard definitions offered by Traitenberg et al. (1997). 


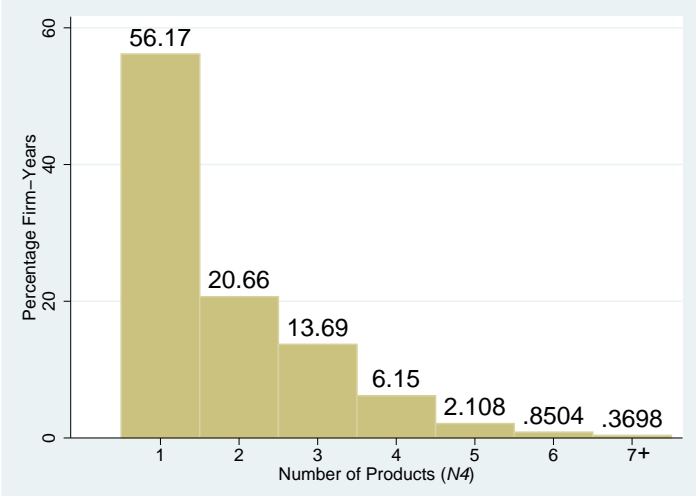

(a)

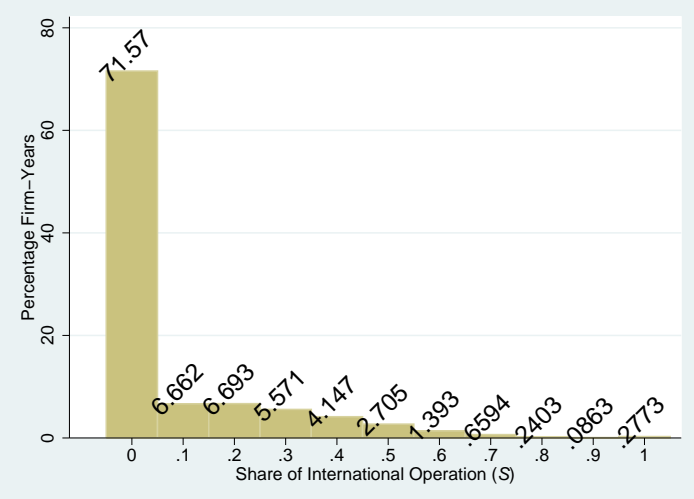

(b)

Figure 2: The distribution of firms bu the number of products and international share of operation.

- Generality

Introduced by Traitenberg et al. (1997), the generality index measures the diversity of citations made to a patent in their technological fields. The index is formally defined as

$$
G E N E R A L=\frac{X G}{X G-1}\left(1-\sum_{k}\left(\frac{X G_{k}}{X G}\right)^{2}\right)
$$

in which $X G$ is the total number of patents that cite a patent, and $X G_{k}$ is the number of patents in technology class $k$ that cite the patent. The measure above is essentially a Herfindal index for the distribution of citing patents. The term $X G /(X G-1)$ is used to adjust for the estimation bias (Hall et al., 2001, Appendix 12). The index returns values closer to one if the patent has been cited in many different technological group, thus is very likely applicable to many diverse fields. In this sense, there is good level of correlation between generality of a patent and our definition of fundamental patent. For technology fields, we diverge from Trajtenberg et al. (1997) and use the USPTO assigned classification codes. The number of classifications used by the USPTO is 422 different fields compared to the 37 fields defined and used by Trajtenberg et al. (1997), hence using the USPTO classification leads to a smaller number of patents with zero generality and more variation in the index.

The major shortcoming of this index is that it is forward looking. Due to the truncation of our patent information in 2006, we are bound to miss some future citations. This problem escalates for 
patents granted in later years. Given that patents can receive citations up to 20 years since their inception (Hall et al., 2001), we anticipate some under-estimation in our generality measure. For this reason, we also resort to a backward looking measure of patent quality described below for robustness check.

\section{- Originality}

Along with the generality of a patent, Trajtenberg et al. (1997) also define the originality of a patent by the diversity of technological fields that the cited patents embody. Although, diversity in citations made does not guarantee diversity in future use, but it is quite possible for patent drawing on a diverse range of fields to get applied to the same diverse fields. The measure is defined as

$$
O R I G I N A L=\frac{X O}{X O-1}\left(1-\sum_{k}\left(\frac{X O_{k}}{X O}\right)^{2}\right)
$$

which, similar to the forward measure, is basically a Herfindal index. $X O$ is the total number of patents cited by a certain patent, and $X O_{k}$ is the number of patents in a technological field cited by the same patent, with technology fields again described as the USPTO assigned classification. The term $X O /(X O-1)$ is similarly used to adjust for the biases. The original adjustment proposed by Hall et al. (2001) also subtracts 1/(XO-1) from ORIGINAL. However, when the Herfindal index is zero (which is a very likely event), then this latter adjustment returned negative values for originality, which is undesirable.

The benefit of using the originality index is that it is backward looking and we observe all patent information as early as 1901. As a result, the index tends to escape the truncation problem that plagues the generality index.

At this point we are mostly equipped with the set of variables that are instrumental to our testing of the theoretical predictions. Table 2 reports the descriptive statistics for this set of variables. In particular, we notice that both the generality and originality indexes have very similar distributions. Regarding the number of products, our firm-years have anything between one to 10 products by either measure of product number. More than half of these firm-years operate fully domestically $(S=0)$, 


\begin{tabular}{lcccccc}
\hline \hline Variable & \#Obs & Mean & Std.Dev. & Min. & Median & Max. \\
\hline GENERAL & 201,211 & 0.476 & 0.329 & 0 & 0.461 & 0.999 \\
OROGINAL & 220,137 & 0.464 & 0.330 & 0 & 0.533 & 0.999 \\
$N 4$ & 16,277 & 1.816 & 1.165 & 1 & 1 & 10 \\
$N 3$ & 16,277 & 1.681 & 1.020 & 1 & 1 & 10 \\
$N H$ & 16,277 & 1.726 & 1.086 & 1 & 1 & 10 \\
$S$ & 16,277 & 0.085 & 0.166 & 0 & 0 & 1 \\
$E M P$ & 16,058 & $9,332.9$ & $32,551.5$ & 1 & 1,474 & 876,800 \\
$R(\$ 000)$ & 16,227 & 374 & 2,561 & 0 & 1.38 & 91,533 \\
$A(\$ 000)$ & 16,227 & 19.11 & 206.4 & 0 & 0 & $16,504.5$ \\
\hline \hline
\end{tabular}

Table 2: Descriptive statistics for the measures of patent quality and other firm characteristics. Statistics for patent quality are at patent level (for those patents that could be matched to a firm), and statistics for the other variables are at firm-year level.

and we already saw in Figure 2 that a very small fraction of firms are fully operating overseas and only headquartered in the U.S. There is much variation in size, research and advertising activities amongst our firm-years. We note that many firm-years in our sample do not spend anything on R\&D or advertisement, though, by comparing medians, the fraction of firm-years that engage in $R \& D$ is larger than those with observable advertising activity.

Table 3 looks at cross relations between these variables by reporting the table of correlations. The generality and originality indexes show a correlation of 0.26 , which points to a positive yet nonoverlapping relationship between the two indexes. At the same time, these indexes show positive correlation with the number of products but negative correlation with the extent of international operation. These preliminary findings are both in line with our prior expectations from the theory. We see smaller correlations between indexes of fundamental innovation and the other variables we composed, namely, size, R\&D stock, and advertising expenditures. On the other hand, both R\&D and advertising are positively related to size, which is expectedly driven by the large profits and resources available to larger firms. The number of products is also positively correlated to size. Binding both size and the number of products to a firm's productivity level makes a good case for this last observation, given the strand of theoretical literature on multi-product firms; see Section 1

Nonetheless, a more interesting finding of this table is that the number of products and the share 


\begin{tabular}{lcccccccc}
\hline \hline & GENERAL & ORIGINAL & $N 4$ & $N 3$ & $N H$ & $S$ & $E M P$ & $R$ \\
\hline ORIGINAL & 0.2630 & & & & & & & \\
$N 4$ & 0.005 & -0.015 & & & & & & \\
$N 3$ & 0.031 & -0.025 & 0.900 & & & & & \\
$N H$ & 0.030 & -0.019 & 0.892 & 0.934 & & & & \\
$S$ & -0.036 & -0.017 & -0.044 & -0.137 & -0.116 & & & \\
$E M P$ & 0.014 & -0.036 & 0.138 & 0.155 & 0.132 & 0.019 & & \\
$R$ & -0.026 & -0.004 & -0.015 & -0.024 & -0.049 & 0.162 & 0.729 & \\
$A$ & -0.027 & 0.016 & -0.093 & -0.093 & -0.108 & 0.050 & 0.255 & 0.776 \\
& & & & & & & & \\
\hline \hline
\end{tabular}

Table 3: The table of correlations between the measured variables. Observations are at patent level (for those patents that are matched to firms).

of international operation are showing a negative relationship, especially when products are defined by their three-digit industry codes. The evidence is, prima facie, in line with recent theories of international trade contemplating that more intense competition that marks MP induces firms to reduce their range of products and focus on their core products instead (See Eckel and Neary, 2010). To seek more details on the exact form of the relationship, the fraction of single and multi-product firms by their share of MP is plotted in Figure 3. A clear pattern is missing, and the figure shows that the relationship is not necessarily a monotnocially positive or negative one over the whole range.

\section{Empirical Results}

\subsection{Econometric Strategy}

In the theoretical section, we build an environment in which multi-product firms are induced to engage in more fundamental innovation due to the diffusive nature of fundamental innovations among several business segments. However, the diminishing effectiveness of fundamental innovation with a larger number of business segments reduces a firm's engagement in this type of innovation. In addition, incremental costs of operating in more product lines increases (decreases) the relative effort in specialized (fundamental) innovation. We also saw that multinationalization of production creates 


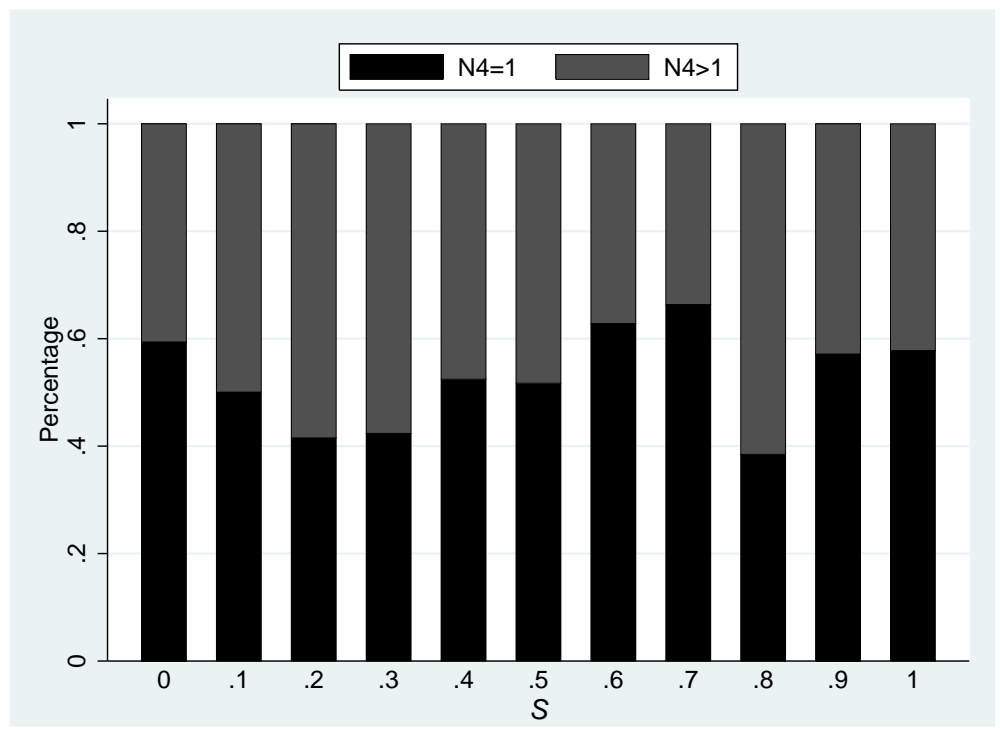

Figure 3: The distribution of single- versus multi-product firms by their share of international operation.

two opposing effects on fundamental innovation. Learning spillovers from foreign markets increase the effectiveness of fundamental innovation, whereas the localized nature of fundamental innovation reduces its effectiveness in foreign plants. Moreover, learning possibilities for firms that are increasing in their product scope make it more likely to generate a combined positive effect on the fundamental component of innovations.

Now that the necessary instruments are in place, we are able to test these implications for our panel of firms with various levels of multinational operation and different number of business segmentation. In particular, our empirical estimations should reveal the sign of the direct effect of (i) product scope and (ii) multinational production on the fundamental nature of innovations. Exploiting the interaction between the two effects, we also determine the impact of (iii) operating in a larger range of product lines on the learning capability of firms engaged in MP, and therefore the overall effect of the latter on the quality of innovation.

Our econometric strategy is driven by the fact that our indexes of fundamental innovation are by construction bounded between zero and one (with a non-trivial mass of zeros). We find the fractional response model of Papke and Wooldridge (1996) the most relevant econometric approach to our prob- 
lem. In this methodology a firm's level of incentive to undertake fundamental research for a particular patent is modeled as an unobserved latent specification which takes the following linear form:

$$
F_{i j t}^{*}=\alpha_{0}+\alpha_{1} N_{j t}+\alpha_{2} S_{j t}+\alpha_{3} N_{j t} \times S_{j t}+X_{j t} \beta+\mu_{i}+\tau_{t}+\xi_{i j t}
$$

where, $F^{*}$ is the latent push for fundamental innovation in patent $i$ applied for by firm $j$ in year $t$. The actual level of indexes for fundamental innovation is determined by a probit transformation of equation (19), or

$$
F_{i j t}=\Phi\left(F_{i j t}^{*}\right)
$$

in which, $\Phi($.$) is the standard normal cumulative distribution. Papke and Wooldridge (1996) show$ that this specification can be simply estimated using a conventional probit approach as if the response variable took only zero and one values.

In our specification, $N_{j t}$ represents the number of products, and we use the variety of measures we defined in the previous section to replace $N_{j t}$. Vector $X_{j t}$ is a set of covariates that would also influence the fundamental nature of patents. We primarily use size, R\&D stock and advertising expenditures. For size, we do not simply use the total employment, as it has a natural positive correlation with the number of products (Table 3). Instead, we think of size as the average number of employees per product (in log terms to control for extreme observations), or

$$
e_{j t}=\log \left(E M P_{j t} / N_{j t}\right)
$$

We also transform the $\mathrm{R} \& \mathrm{D}$ stock and advertising expenditure using the inverse hyperbolic sine transformation proposed by Burbidge et al. (1988) before including them in $X$. The transformation has the form

$$
r_{j t}=\log \left(R_{j t}+\sqrt{R_{j t}^{2}+1}\right), \quad a_{j t}=\log \left(A_{j t}+\sqrt{A_{j t}^{2}+1}\right) .
$$

The transformation has the desired property that it limits the effect of extreme values, while leaving the smaller values practically untouched. Compared to the log transformation, it has the added property 
that it preserves observations with zero values. Table 2 shows that there is a considerable mass of firms with zero R\&D stock or zero advertising, and we did not want to lose those observations. Finally, we include a dummy variable which is equal to one when a firm's number of 4-digit segments increased from year $t$ to $t+1(A D D)$. This last variable addresses the possibility that adding products is led by patents that are more product-specific and less fundamental.

There are a number of controls that we use in our specification. In case patenting in some fields inherently requires a higher degree of fundamental innovation, the effect is absorbed by the dummies, $\mu_{j}$, for the two-digit patent technology classes defined by Hall et al. (2001). We also control for the effect of business cycles on innovation and patenting activities by including year dummies.

Other unobserved firm heterogeneities will be left to $\xi_{i j t}$. As a result, the disturbance terms could be correlated inter-temporally due to firm fixed effects. In a fractional response model, it is not trivial to separate this correlated component from the disturbance term by effectively controlling for firm fixed-effect or by brute force (defining a dummy for each firm-year, but our limited computational resources does not allow us to do so). Instead, we follow Papke and Wooldridge (2008) to partially control for the fixed effects. They specifically simplify the problem by assuming that the fixed effects are a linear combination of the continuous variables in the latent model averaged over time for each individual. In our case, an appropriate fixed effect model will be

$$
\xi_{i j, t}=\iota_{j}+\tilde{\beta}_{1} \bar{e}_{j}+\tilde{\beta}_{2} \bar{r}_{j}+\tilde{\beta}_{3} \bar{a}_{j}+\gamma_{1} n p_{0}+\gamma_{2} S_{0}+\gamma_{3} N_{0}+\epsilon_{i j t} .
$$

First of all, we control for the main industry of operation and also include the averages for our explanatory continuous variables. We further enhance our fixed-effect specification by adding a set of pre-sample averages. Blundell et al. (1999) have used such approach when dealing with the number of patent occurrences, reasoning that a firm's past experience has a decisive role in its future innovation path. In our model, we resort to a more elaborate description of a firm's past experience by including the average number of patents per year ( $n p$, with the possibility of zero patents and also transformed by inverse hyperbolic sine function), the average number of 4-digit product lines $\left(N_{0}\right)$, and the average share of international operation $S_{0}$. All averages are taken by firm and over the pre-sample years of 
$1976-1984$.

Disturbances across patents in the same year could also be correlated. This correlation is, however, more of a clustered nature as firm-level shocks are expected to affect the indexes of fundamental innovation in the same direction for all patents within a firm in a particular year. For this reason, we cluster the disturbance $\epsilon_{i j t}$ by firm to account for any remaining cross-correlations not accounted for by the described fixed-effect model. If there is a common shock affecting all firms in the same year, it is already absorbed by the year dummies we included in the main specification.

The form of the fixed-effect model in (21) effectively partitions the continuous variables into $x_{j t}=$ $\bar{x}_{j}+\Delta x_{j t}$. This observation allows us to restructure (19) into

$$
C_{i j t}^{*}=\alpha_{0}+\alpha_{1} N_{j t}+\alpha_{2} S_{j t}+\alpha_{3} N_{j t} \times S_{j t}+\Delta X_{j t} \beta+\mu_{i}+\tau_{t}+\xi_{i j t}
$$

where $\xi_{i j t}$ is modeled as (21). In what follows, we will focus on the results from estimating (22).

\subsection{Estimation Results}

Estimating our fractional response model generates the results listed in Table 4. In the first three columns the dependent variable is the index of generality, and in the last three columns the dependent variable is the index of originality. Each model is estimated using different measures for the number of products defined in Section 4 for robustness check.

The table shows a consistent picture in which a larger share of international operation negatively impacts the fundamental nature of patents, whether measured as generality or originality. In all cases, however, this negative effect is offset by a positive interaction term which gets magnified as the number of products grows. A larger number of products, per se, also has a negative impact on the fundamental nature of patents. This last effect conforms to the hypothesis that fundamental innovation is beneficial to all products, though the benefit thins out quickly for individual products in a multi-product environment.

We notice that other explanatory variables have also interesting implications. The most useful results are indeed those of the average variables (fixed-effect terms). The average size of products, $\bar{e}$, 


\begin{tabular}{|c|c|c|c|c|c|c|}
\hline \multirow{3}{*}{$\frac{\text { Variable }}{S_{t}}$} & \multicolumn{6}{|c|}{ Dependent Variable } \\
\hline & \multicolumn{3}{|c|}{$G E N E R A L_{t}$} & \multicolumn{3}{|c|}{$O R I G I N A L_{t}$} \\
\hline & $\begin{array}{c}-0.077^{* *} \\
(0.035)\end{array}$ & $\begin{array}{c}-0.107^{* * *} \\
(0.036)\end{array}$ & $\begin{array}{c}-0.098^{* * *} \\
(0.035)\end{array}$ & $\begin{array}{c}-0.103^{* * *} \\
(0.037)\end{array}$ & $\begin{array}{c}-0.115^{* * *} \\
(0.037)\end{array}$ & $\begin{array}{c}-0.102^{* * *} \\
(0.036)\end{array}$ \\
\hline$N 4_{t}$ & $\begin{array}{c}-0.014^{* * *} \\
(0.004)\end{array}$ & & & $\begin{array}{c}-0.017^{* * *} \\
(0.004)\end{array}$ & & \\
\hline$N 4_{t} \times S_{t}$ & $\begin{array}{c}0.010 \\
(0.009)\end{array}$ & & & $\begin{array}{c}0.033^{* * *} \\
(0.010)\end{array}$ & & \\
\hline$N 3_{t}$ & & $\begin{array}{c}-0.013^{* * *} \\
(0.004)\end{array}$ & & & $\begin{array}{c}-0.020^{* * *} \\
(0.005)\end{array}$ & \\
\hline$N 3_{t} \times S_{t}$ & & $\begin{array}{c}0.027^{* *} \\
(0.012)\end{array}$ & & & $\begin{array}{c}0.045^{* * *} \\
(0.013)\end{array}$ & \\
\hline$N H_{t}$ & & & $\begin{array}{c}-0.015^{* * *} \\
(0.004)\end{array}$ & & & $\begin{array}{c}-0.012^{* * *} \\
(0.004)\end{array}$ \\
\hline$N H_{t} \times S_{t}$ & & & $\begin{array}{c}0.020^{* *} \\
(0.010)\end{array}$ & & & $\begin{array}{c}0.034^{* * *} \\
(0.011)\end{array}$ \\
\hline $\bar{e}_{t}$ & $\begin{array}{c}0.002 \\
(0.005)\end{array}$ & $\begin{array}{c}0.003 \\
(0.005)\end{array}$ & $\begin{array}{c}0.003 \\
(0.005)\end{array}$ & $\begin{array}{l}-0.004 \\
(0.005)\end{array}$ & $\begin{array}{l}-0.003 \\
(0.005)\end{array}$ & $\begin{array}{l}-0.003 \\
(0.005)\end{array}$ \\
\hline$\Delta e_{t}$ & $\begin{array}{c}-0.026^{* * *} \\
(0.010)\end{array}$ & $\begin{array}{l}-0.014 \\
(0.009)\end{array}$ & $\begin{array}{c}-0.018^{* *} \\
(0.009)\end{array}$ & $\begin{array}{c}-0.021^{* *} \\
(0.010)\end{array}$ & $\begin{array}{c}-0.017^{*} \\
(0.009)\end{array}$ & $\begin{array}{c}-0.012 \\
(0.009)\end{array}$ \\
\hline $\bar{r}_{t}$ & $\begin{array}{c}0.044^{* * *} \\
(0.006)\end{array}$ & $\begin{array}{c}0.041^{* * *} \\
(0.006)\end{array}$ & $\begin{array}{c}0.042^{* * *} \\
(0.007)\end{array}$ & $\begin{array}{c}0.049^{* * *} \\
(0.007)\end{array}$ & $\begin{array}{c}0.048^{* * *} \\
(0.007)\end{array}$ & $\begin{array}{c}0.048^{* * *} \\
(0.007)\end{array}$ \\
\hline$\Delta r_{t}$ & $\begin{array}{c}0.016 \\
(0.014)\end{array}$ & $\begin{array}{c}0.016 \\
(0.014)\end{array}$ & $\begin{array}{c}0.019 \\
(0.015)\end{array}$ & $\begin{array}{l}-0.005 \\
(0.013)\end{array}$ & $\begin{array}{l}-0.004 \\
(0.013)\end{array}$ & $\begin{array}{c}-0.006 \\
(0.013)\end{array}$ \\
\hline $\bar{a}_{t}$ & $\begin{array}{c}-0.075^{* * *} \\
(0.024)\end{array}$ & $\begin{array}{c}-0.078^{* * *} \\
(0.024)\end{array}$ & $\begin{array}{c}-0.077^{* * *} \\
(0.024)\end{array}$ & $\begin{array}{c}-0.176^{* * *} \\
(0.024)\end{array}$ & $\begin{array}{c}-0.178^{* * *} \\
(0.024)\end{array}$ & $\begin{array}{c}-0.181^{* * *} \\
(0.023)\end{array}$ \\
\hline$\Delta a_{t}$ & $\begin{array}{c}0.026 \\
(0.017)\end{array}$ & $\begin{array}{c}0.023 \\
(0.017)\end{array}$ & $\begin{array}{c}0.023 \\
(0.017)\end{array}$ & $\begin{array}{c}0.065^{* * *} \\
(0.020)\end{array}$ & $\begin{array}{c}0.064^{* * *} \\
(0.020)\end{array}$ & $\begin{array}{c}0.063^{* * *} \\
(0.020)\end{array}$ \\
\hline$A D D_{t}$ & $\begin{array}{c}0.001 \\
(0.009)\end{array}$ & $\begin{array}{c}0.002 \\
(0.009)\end{array}$ & $\begin{array}{c}0.000 \\
(0.009)\end{array}$ & $\begin{array}{c}0.005 \\
(0.010)\end{array}$ & $\begin{array}{c}0.005 \\
(0.010)\end{array}$ & $\begin{array}{c}0.007 \\
(0.010)\end{array}$ \\
\hline Log Likelihood & -117605.1 & -117607.2 & -117604.3 & -127829.8 & -127829.1 & -127833.5 \\
\hline \#Obs & 214,592 & 214,592 & 214,592 & 231,754 & 231,754 & 231,754 \\
\hline
\end{tabular}

Table 4: The estimated coefficients for the fractional response model of fundamental innovation. The numbers in parentheses are standard errors clustered by firm-year. ${ }^{*},{ }^{* *}$, and ${ }^{* * *}$ indicate significance at $10 \%, 5 \%$, and $1 \%$, respectively. The sample is at firm-year-patent level. 
does not seem to have any trivial effect on indexes of fundamental innovation, although it seems to us that temporary increases, $\delta e$, are a sign of increased focus on production and less focus on innovation and accordingly cause a reduction in the indexes. Average $R \& D$ expenditure has a positive and significant influence on the indexes which was well anticipated. We also hypothesized that larger advertising spendings reduce incentive for fundamental innovation and signal a more commercial (product-specific) approach to innovation, which is evident from the estimated coefficient for average advertising. Contrary to what we expected, adding products $(A D D)$ doe not play any role in the model, and the results are both economically and statistically insignificant.

In the models above, all activities are taking place during the same period. A timing issue could cause, for instance, a non-fundamental (more specialized) patent leading to the introduction of a new or improved product, which, in turn, increases the number of products. As a result, the direction of causality from the number of products to the indexes of fundamental innovation gets somewhat blurred. Also, patenting products in the anticipation of moving its production overseas could also add to the endogeneity issue. To explore the extent to which our results are affected by these issues, we also estimate a lagged model of the following form:

$$
C_{i j, t+1}^{*}=\alpha_{0}+\alpha_{1} N_{j t}+\alpha_{2} S_{j t}+\alpha_{3} N_{j t} \times S_{j t}+\Delta X_{j t} \beta+\tau_{t}+\nu_{i j t}
$$

In $X_{j t}$ we are including the same explanatory variables as before, except that adding a product, $A D D_{t+1}$, is contemporaneous: we believe that products added with (and not before) a patent are an important indication of the role for fundamental innovation. The disturbance term $\nu_{i j t}$ is also structured in the same way as (21) to deal with the firm-fixed effects, with $\epsilon_{i j t}$ clustered by firm.

This second set of estimation results are listed in Table 5 . We do not see any significant shift from the previous results. International operation is still casting a negative effect, while the interaction term offsets that negative role. Operating with a larger number of products is also reducing the fundamental aspect of the indexes as before. We also find the same implications pertaining to the control variables 7

\footnotetext{
${ }^{7}$ We notice that a number of patents are missing generality or originality index because they have no citation or they are not being cited. In the case of originality, we tested for selection bias by using the same fractional response model but by applying the selection correction of Van de Ven and van Praag (1981), with the implications showing robustness to the selection effect. With generality, we faced two problems: first, a patent not being cited has less to do with its
} 


\begin{tabular}{|c|c|c|c|c|c|c|}
\hline \multirow{3}{*}{$\frac{\text { Variable }}{S_{t}}$} & \multicolumn{6}{|c|}{ Dependent Variable } \\
\hline & \multicolumn{3}{|c|}{$G E N E R A L_{t+1}$} & \multicolumn{3}{|c|}{$O R I G I N A L_{t+1}$} \\
\hline & $\begin{array}{c}-0.094^{* *} \\
(0.037)\end{array}$ & $\begin{array}{c}-0.110^{* * *} \\
(0.037)\end{array}$ & $\begin{array}{c}-0.110^{* * *} \\
(0.036)\end{array}$ & $\begin{array}{c}-0.099^{* *} \\
(0.039)\end{array}$ & $\begin{array}{c}-0.100^{* * *} \\
(0.039)\end{array}$ & $\begin{array}{c}-0.105^{* * *} \\
(0.037)\end{array}$ \\
\hline$N 4_{t}$ & $\begin{array}{c}-0.016^{* * *} \\
(0.004)\end{array}$ & & & $\begin{array}{c}-0.018^{* * *} \\
(0.004)\end{array}$ & & \\
\hline$N 4_{t} \times S_{t}$ & $\begin{array}{l}0.017^{*} \\
(0.009)\end{array}$ & & & $\begin{array}{c}0.035^{* * *} \\
(0.010)\end{array}$ & & \\
\hline$N 3_{t}$ & & $\begin{array}{c}-0.017^{* * *} \\
(0.004)\end{array}$ & & & $\begin{array}{c}-0.021^{* * *} \\
(0.005)\end{array}$ & \\
\hline$N 3_{t} \times S_{t}$ & & $\begin{array}{c}0.027^{* *} \\
(0.012)\end{array}$ & & & $\begin{array}{c}0.042^{* * *} \\
(0.013)\end{array}$ & \\
\hline$N H_{t}$ & & & $\begin{array}{c}-0.016^{* * *} \\
(0.004)\end{array}$ & & & $\begin{array}{c}-0.016^{* * *} \\
(0.004)\end{array}$ \\
\hline$N H_{t} \times S_{t}$ & & & $\begin{array}{c}0.025^{* *} \\
(0.010)\end{array}$ & & & $\begin{array}{c}0.041^{* * * *} \\
(0.011)\end{array}$ \\
\hline $\bar{e}_{t}$ & $\begin{array}{c}0.008 \\
(0.005)\end{array}$ & $\begin{array}{c}0.008 \\
(0.005)\end{array}$ & $\begin{array}{c}0.009 \\
(0.005)\end{array}$ & $\begin{array}{c}0.001 \\
(0.005)\end{array}$ & $\begin{array}{c}0.000 \\
(0.005)\end{array}$ & $\begin{array}{c}0.002 \\
(0.005)\end{array}$ \\
\hline$\Delta e_{t}$ & $\begin{array}{c}-0.031^{* * *} \\
(0.010)\end{array}$ & $\begin{array}{c}-0.023^{* *} \\
(0.009)\end{array}$ & $\begin{array}{c}-0.024^{* * *} \\
(0.009)\end{array}$ & $\begin{array}{l}-0.017 \\
(0.011)\end{array}$ & $\begin{array}{l}-0.014 \\
(0.010)\end{array}$ & $\begin{array}{l}-0.008 \\
(0.010)\end{array}$ \\
\hline $\bar{r}_{t}$ & $\begin{array}{c}0.037^{* * *} \\
(0.007)\end{array}$ & $\begin{array}{c}0.036^{* * *} \\
(0.007)\end{array}$ & $\begin{array}{c}0.036^{* * *} \\
(0.007)\end{array}$ & $\begin{array}{c}0.051^{* * *} \\
(0.007)\end{array}$ & $\begin{array}{c}0.051^{* * *} \\
(0.007)\end{array}$ & $\begin{array}{c}0.050^{* * *} \\
(0.007)\end{array}$ \\
\hline$\Delta r_{t}$ & $\begin{array}{c}0.038^{* *} \\
(0.015)\end{array}$ & $\begin{array}{c}0.038^{* *} \\
(0.015)\end{array}$ & $\begin{array}{c}0.040^{* * *} \\
(0.015)\end{array}$ & $\begin{array}{l}-0.016 \\
(0.014)\end{array}$ & $\begin{array}{l}-0.015 \\
(0.014)\end{array}$ & $\begin{array}{l}-0.015 \\
(0.014)\end{array}$ \\
\hline $\bar{a}_{t}$ & $\begin{array}{c}-0.054^{* *} \\
(0.024)\end{array}$ & $\begin{array}{c}-0.057^{* *} \\
(0.024)\end{array}$ & $\begin{array}{c}-0.056^{* *} \\
(0.024)\end{array}$ & $\begin{array}{c}-0.199^{* * *} \\
(0.026)\end{array}$ & $\begin{array}{c}-0.201^{* * *} \\
(0.025)\end{array}$ & $\begin{array}{c}-0.202^{* * *} \\
(0.025)\end{array}$ \\
\hline$\Delta a_{t}$ & $\begin{array}{c}0.006 \\
(0.021)\end{array}$ & $\begin{array}{c}0.004 \\
(0.021)\end{array}$ & $\begin{array}{c}0.002 \\
(0.021)\end{array}$ & $\begin{array}{c}0.074^{* * *} \\
(0.024)\end{array}$ & $\begin{array}{c}0.074^{* * *} \\
(0.024)\end{array}$ & $\begin{array}{c}0.071^{* * *} \\
(0.024)\end{array}$ \\
\hline$A D D_{t+1}$ & $\begin{array}{c}0.004 \\
(0.008)\end{array}$ & $\begin{array}{c}0.002 \\
(0.008)\end{array}$ & $\begin{array}{c}0.002 \\
(0.008)\end{array}$ & $\begin{array}{c}0.005 \\
(0.010)\end{array}$ & $\begin{array}{c}0.004 \\
(0.010)\end{array}$ & $\begin{array}{c}0.004 \\
(0.010)\end{array}$ \\
\hline Log Likelihood & -107135.0 & -107136.1 & -107134.4 & -118597.9 & -118598.6 & -118599.3 \\
\hline \#Obs & 200,777 & 200,777 & 200,777 & 219,628 & 219,628 & 219,628 \\
\hline
\end{tabular}

Table 5: The estimated coefficients for the fractional response model of one-time lag. The numbers in parentheses are standard errors clustered by firm-year. *,**, and *** indicate significance at $10 \%$, $5 \%$, and $1 \%$, respectively. The sample is at firm-year-patent level. 
As our last exercise, we would like to highlight that there is a major, and mostly contrasting, difference between describing a firm's quality of research in terms of the number of patents as opposed to the fundamental nature of those patents. For this purpose, we form the counts of patents by firms in a year $(P A T)$ by aggregating our sample of firm-year-patents. Let the average number of patents applied for by a firm follow a linear specification of the form

$$
E\left[P A T_{j t} \mid N_{j t}, S_{j t}, X_{j t}\right]=\alpha_{0}+\alpha_{1} N_{j t}+\alpha_{2} S_{j t}+\alpha_{3} N_{j t} \times S_{j t}+X_{j t} \beta+\tau_{t}+\eta_{i j t}
$$

The average number of patents can then be treated as the parameter in a Poisson distribution, and the coefficients are estimated using a Poisson regression. For comparability, we also include the same fixed-effect structure as above. Table 6 reports the estimation results. To also explore the timing issue, we estimate the same model in a lagged formation as we did with the indexes of fundamental innovation.

In these results, we see a major shift. Increasing the share of international operation is leading to substantially larger number of patents. Part of this trend can be explained by firms trying to protect their intellectual property rights from spilling over to the foreign firms when moving overseas. Investigating those firms in COMPUSTAT that report moving part of operation to East Asia, in particular, shows that patenting among those firms spikes just before and after offshoring. Our explanation for these particular behavior is that these firms are keen on self-protection by some form of binding legal procedure at home, when contract enforcement is weak in the destination country, so as to give themselves the ability to block the U.S. market to those foreign firms that engage in opportunistic behavior as a punishing measure. The results of Table 6 suggest that these patents are more specific to the product they are supposed to protect rather than pertaining to a fundamental innovation activity.

In another contrasting shift, having more products increases the average number of patents, while the interaction term is now negative. The negative effect of the interaction term is actually multiplied by the number of products, which becomes a dominant force when firms are operating in foreign

observables than with unobserved characteristics of future patents. Second, due to the truncation in years we might have a not-cited patent that could be cited in later years. The two issues combined render the selection approach distorted and meaningless. We confirmed our suspicion by actually estimating the selection model with generality, which led to grossly insignificant effects especially for the main variables of interest. 


\begin{tabular}{|c|c|c|c|c|c|c|}
\hline \multirow[b]{2}{*}{ Variable } & \multicolumn{6}{|c|}{ "Dependent Variable } \\
\hline & $P A T_{t}$ & $\overline{P A T_{t}}$ & $P A T_{t}$ & $P A T_{t+1}$ & $P A T_{t+1}$ & $P A T_{t+1}$ \\
\hline$\overline{S_{t}}$ & $\begin{array}{c}0.492^{* * *} \\
(0.175)\end{array}$ & $\begin{array}{c}0.594^{* * *} \\
(0.176)\end{array}$ & $\begin{array}{c}0.592^{* * *} \\
(0.168)\end{array}$ & $\begin{array}{c}0.567^{* * *} \\
(0.191)\end{array}$ & $\begin{array}{c}0.681^{* * *} \\
(0.188)\end{array}$ & $\begin{array}{c}0.607^{* * *} \\
(0.181)\end{array}$ \\
\hline$N 4_{t}$ & $\begin{array}{c}0.076^{* * *} \\
(0.016)\end{array}$ & & & $\begin{array}{c}0.083^{* * *} \\
(0.018)\end{array}$ & & \\
\hline$N 4_{t} \times S_{t}$ & $\begin{array}{c}-0.094^{* *} \\
(0.040)\end{array}$ & & & $\begin{array}{c}-0.125^{* * *} \\
(0.047)\end{array}$ & & \\
\hline$N 3_{t}$ & & $\begin{array}{c}0.078^{* * *} \\
(0.018)\end{array}$ & & & $\begin{array}{c}0.083^{* * *} \\
(0.020)\end{array}$ & \\
\hline$N 3_{t} \times S_{t}$ & & $\begin{array}{c}-0.157^{* * *} \\
(0.048)\end{array}$ & & & $\begin{array}{c}-0.205^{* * *} \\
(0.056)\end{array}$ & \\
\hline$N H_{t}$ & & & $\begin{array}{c}0.068^{* * *} \\
(0.016)\end{array}$ & & & $\begin{array}{c}0.057^{* * *} \\
(0.018)\end{array}$ \\
\hline$N H_{t} \times S_{t}$ & & & $\begin{array}{c}-0.149^{* * *} \\
(0.041)\end{array}$ & & & $\begin{array}{c}-0.158^{* * * *} \\
(0.049)\end{array}$ \\
\hline $\bar{e}_{t}$ & $\begin{array}{c}0.505^{* * *} \\
(0.018)\end{array}$ & $\begin{array}{c}0.502^{* * *} \\
(0.018)\end{array}$ & $\begin{array}{c}0.498^{* * *} \\
(0.018)\end{array}$ & $\begin{array}{c}0.516^{* * *} \\
(0.018)\end{array}$ & $\begin{array}{c}0.513^{* * *} \\
(0.018)\end{array}$ & $\begin{array}{c}0.512^{* * *} \\
(0.018)\end{array}$ \\
\hline$\Delta e_{t}$ & $\begin{array}{c}0.483^{* * *} \\
(0.040)\end{array}$ & $\begin{array}{c}0.441^{* * *} \\
(0.037)\end{array}$ & $\begin{array}{c}0.432^{* * *} \\
(0.036)\end{array}$ & $\begin{array}{c}0.507^{* * *} \\
(0.043)\end{array}$ & $\begin{array}{c}0.464^{* * *} \\
(0.041)\end{array}$ & $\begin{array}{c}0.444^{* * *} \\
(0.039)\end{array}$ \\
\hline $\bar{r}_{t}$ & $\begin{array}{c}0.000 \\
(0.028)\end{array}$ & $\begin{array}{c}0.008 \\
(0.028)\end{array}$ & $\begin{array}{c}0.010 \\
(0.028)\end{array}$ & $\begin{array}{c}0.019 \\
(0.030)\end{array}$ & $\begin{array}{c}0.026 \\
(0.030)\end{array}$ & $\begin{array}{c}0.024 \\
(0.030)\end{array}$ \\
\hline$\Delta r_{t}$ & $\begin{array}{c}1.179^{* * *} \\
(0.092)\end{array}$ & $\begin{array}{c}1.179^{* * *} \\
(0.093)\end{array}$ & $\begin{array}{c}1.178^{* * *} \\
(0.093)\end{array}$ & $\begin{array}{c}1.134^{* * *} \\
(0.103)\end{array}$ & $\begin{array}{c}1.135^{* * *} \\
(0.105)\end{array}$ & $\begin{array}{c}1.150^{* * *} \\
(0.105)\end{array}$ \\
\hline $\bar{a}_{t}$ & $\begin{array}{c}0.103 \\
(0.113)\end{array}$ & $\begin{array}{c}0.117 \\
(0.113)\end{array}$ & $\begin{array}{c}0.130 \\
(0.112)\end{array}$ & $\begin{array}{c}0.165 \\
(0.118)\end{array}$ & $\begin{array}{c}0.179 \\
(0.119)\end{array}$ & $\begin{array}{c}0.190 \\
(0.118)\end{array}$ \\
\hline$\Delta a_{t}$ & $\begin{array}{c}-0.393^{* *} \\
(0.164)\end{array}$ & $\begin{array}{c}-0.348^{* *} \\
(0.159)\end{array}$ & $\begin{array}{c}-0.317^{* *} \\
(0.159)\end{array}$ & $\begin{array}{c}-0.868^{* * *} \\
(0.203)\end{array}$ & $\begin{array}{c}-0.797^{* * *} \\
(0.197)\end{array}$ & $\begin{array}{c}-0.774^{* * *} \\
(0.198)\end{array}$ \\
\hline$A D D_{t}$ & $\begin{array}{c}-0.235^{* * *} \\
(0.048)\end{array}$ & $\begin{array}{c}-0.240^{* * *} \\
(0.049)\end{array}$ & $\begin{array}{c}-0.241^{* * *} \\
(0.049)\end{array}$ & $\begin{array}{c}-0.299^{* * *} \\
(0.055)\end{array}$ & $\begin{array}{c}-0.305^{* * *} \\
(0.056)\end{array}$ & $\begin{array}{c}-0.312^{* * *} \\
(0.056)\end{array}$ \\
\hline Log Likelihood & -61553.1 & -61608.4 & -61588.1 & -60213.5 & -60244.6 & -60335.0 \\
\hline \#Obs & 15,987 & 15,987 & 15,987 & 14,896 & 14,896 & 14,896 \\
\hline
\end{tabular}

Table 6: The estimated coefficients for the Poisson regression with the number of patents as the dependent variable. The numbers in parentheses are robust standard errors. ${ }^{*},{ }^{* *}$, and ${ }^{* * *}$ indicate significance at $10 \%, 5 \%$, and $1 \%$, respectively. The sample is at firm-year level. 
countries. Average employment per product has a positive effect, that is, firms with larger product lines file for a larger number of patents. Adding a product, on the other hand, seems to reduce the number of patents. It seems to us that this negative trend has to do with the tradeoff between protecting your intellectual property by patenting versus keeping it a trade secrets. We do not pursue this hypothesis any further and leave it for future research, as it is out of scope for this paper and we do not have sufficient information to track unpatented innovations. Stock of $R \& D$ and advertising are not a deciding force in this specification, with both factors showing small and statistically insignificant effects. Our conclusion from this part of results is that the mere act of patenting does not necessarily indicate quality nor the commercial promise of an innovation.

\section{Conclusion}

In this paper, we provide a theoretical framework and evidence to corroborate previous findings on the localized nature of knowledge spillovers. We show however that in a multi-product environment, multinationalization of production increases the scope of acquiring knowledge - more so when a firm engages in a diversified portfolio of products. Two features define our theoretical prediction. First, specialized innovation is limited to one product line, but can be easily transferred and used (internationally) in multiple locations. In contrast, fundamental innovation can be applied to several product lines but is geographically more difficult to transfer abroad to foreign production sites. This is in line with vast existing evidence among which are surveys on multinationals summarized in Mansfield et al. (1979), Kuemmerle (1999), Frost and Ensign (2002), and Naghavi and Comune (2012) for several industries and in different countries. These studies suggest that fundamental innovation continues to take place in the headquarter home location of firms, while the $R \& D$ in subsidiaries tends to focus on incremental or adaptation efforts and the application of existing scientific and technical knowledge. Second, we emphasize learning spillovers that occur from international operations and how these can increase in their magnitude when a firm is active in more product lines regardless of the diseconomies of scope. This is in line with the concept in Noteboom (2000) that the heterogeneity of knowledge is essential for learning and should be "sufficiently small to allow for understanding, but sufficiently 
large to yield non-redundant knowledge." Moreover, we add the concept of learning to the hypothesis by Nelson (1959) by stating that firms operating in diverse industries are able to do more research of a fundamental nature by learning externality that arise from their multinational activities.

The key insight to our analysis derives from pinning down the quality of patents, as to an invention that can create substantial external benefits. This is an important distinction in the spirit of Boldrin and Levine (2013), who strongly argue against the notion that patents serve to increase innovation and productivity. Indeed, the number of patents have quadrupled in the past three decades without being accompanied by any upward trend in $R \& D$ expenditure or factor productivity. The lack of any solid empirical evidence that identifies productivity with the number of patents suggests other forces to be at play and innovation to have a multifaceted character 8

We are particularly concerned with the applicability of a patent to diverse industries as an indication that the innovation that led to a patent draws on a vast pool of knowledge. We define this as fundamental research and follow Trajtenberg et al. (1997) to describe it in two dimensions. The first looks at citations made to a patent previously referred to as generality to measure the diversity of citations made to a patent in their technological fields. To check the robustness of our results, we then use a backward looking index that looks at the citation made by the patent to define the diversity of technological fields that the cited patents embody. The results highlight both the positive and the negative effect of MP on the two types of innovation and show that they move in opposite directions and that the net impact depends on the product scope of firms.

Although our approach does not take into consideration cost heterogeneities among products of a firm, the notion of innovation in our model parallels that in Eckel et al. (2011), where the two kinds of investment are made on quality rather than process innovation. In their work, a more broad type of innovation could enhance the attractiveness of the firm's brand (i.e. all products), while a more specific innovation improves only the quality of an individual product. Interestingly, they show that a higher level of product differentiation induces firms to invest relatively more in the quality of individual varieties than in the quality of their overall brand. An interesting extension of the current framework would be to account for the distance of a variety from the core competence of a firm in

\footnotetext{
${ }^{8}$ Another interesting paragon to characterize different levels of innovation is how Acemoglu et al. (2006) distinguish between innovation and the adoption of existing technologies.
} 
order to distinguish between innovation aimed at the quality of its core competence as opposed to more generic attempts to improve the overall performance of firms. Doing so allows us to study yet another dimension of MP by looking at how multinationalization impacts the innovation decision of firms in their core and non-core sectors.

\section{References}

Acemoglu, D., Aghion, P., and Zilibotti, F. (2006). "Distance to frontier, selection, and economic growth". Journal of the European Economic Association, 4(1):37-74.

Akcigit, U. and Kerr, W. R. (2012). "Growth through heterogeneous innovations". Working Papers 12-08, Center for Economic Studies, U.S. Census Bureau.

Arkolakis, C., Ramondo, N., Rodríguez-Clare, A., and Yeaple, S. (2012). "Innovation and production in the global economy". Mimeo.

Atkeson, A. and Burstein, A. T. (2010). "Innovation, firm dynamics, and international trade". Journal of Political Economy, 118(3):433-484.

Audretsch, D. B. and Feldman, M. P. (1996). "R\&D spillovers and the geography of innovation and production". American Economic Review, 86(3):630-40.

Baldwin, R. E. and Ottaviano, G. I. P. (2001). "Multiproduct multinationals and reciprocal FDI dumping". Journal of International Economics, 54(2):429-448.

Bartelsman, E. J. and Gray, W. (1996). "The NBER manufacturing productivity database". NBER Working Papers 205, National Bureau of Economic Research, Inc.

Bernard, A. B. and Jensen, J. B. (1999). "Exceptional exporter performance: cause, effect, or both?" Journal of International Economics, 47(1):1-25.

Bernard, A. B., Redding, S. J., and Schott, P. K. (2011). "Multiproduct firms and trade liberalization". The Quarterly Journal of Economics, 126(3):1271-1318. 
Bloom, N., Schankerman, M., and Reenen, J. V. (2013). "Identifying technology spillovers and product market rivalry". Econometrica, forthcoming.

Blundell, R., Griffith, R., and Reenen, J. V. (1999). "Maket shares, market value and innovation in a panel of British manufacturing firms". Review of Economic Studies, 66(3):529-554.

Boldrin, M. and Levine, D. K. (2013). "The case against patents". Technical report.

Brambilla, I. (2009). "Multinationals, technology, and the introduction of varieties of goods". Journal of International Economics, 79(1):89-101.

Branstetter, L. G. (2001). "Are knowledge spillovers international or intranational in scope?: Microeconometric evidence from the U.S. and Japan". Journal of International Economics, 53(1):53-79.

Burbidge, J. B., Magee, L., and Robb, A. L. (1988). "Alternative transformations t handle extreme values of the dependent variable". Journal of the American Statistical Association, 83(401):123-127.

Clarke, D. G. (1976). "Econometric measurement of the duration of advertisement effect on sales". Journal of Marketing Research, 13(4):345-357.

Criscuolo, C., Haskel, J. E., and Slaughter, M. J. (2010). "Global engagement and the innovation activities of firms". International Journal of Industrial Organization, 28(2):191-202.

Dhingra, S. (2013). "Trading away wide brands for cheap brands". American Economic Review, forthcoming.

Eckel, C., Iacovone, L., Javorcik, B., and Neary, J. P. (2011). "Multi-product firms at home and away: Cost- versus quality-based competence". CEPR Discussion Papers 8186, C.E.P.R. Discussion Papers.

Eckel, C. and Neary, J. P. (2010). "Multi-product firms and flexible manufacturing in the global economy". Review of Economic Studies, 77(1):188-217.

Frost, J. M. B., Tony S. and Ensign, P. C. (2002). "Centres of excellence in multinational corporations". Strategic Management Journal, 23(11):997-1015. 
Hall, B. H. (1990). "The manufcaturing sector master file: 1959-1987". NBER Working Papers 3366, National Bureau of Economic Research, Inc.

Hall, B. H., Jaffe, A. B., and Trajtenberg, M. (2001). "The NBER patent citation data file: Lessons, insights and methodological tools". NBER Working Papers 8498, National Bureau of Economic Research, Inc.

Helpman, E. (1984). "A simple theory of international trade with multinational corporations". Journal of Political Economy, 92(3):451-71.

Helpman, E., Melitz, M. J., and Yeaple, S. R. (2004). "Export versus FDI with heterogeneous firms". American Economic Review, 94(1):300-316.

Jaffe, A. B., Trajtenberg, M., and Henderson, R. (1993). "Geographic localization of knowledge spillovers as evidenced by patent citations". The Quarterly Journal of Economics, 108(3):577-98.

Keller, W. (2002). "Geographic localization of international technology diffusion". American Economic Review, 92(1):120-142.

Kuemmerle, W. (1999). "Foreign direct investment in industrial research in the pharmaceutical and electronics industries-results from a survey of multinational firms". Research Policy, 28(2-3):179193.

Lychagin, S., Pinkse, J., Slade, M. E., and Reenen, J. V. (2010). "Spillovers in space: Does geography matter?" CEP Discussion Papers dp0991, Centre for Economic Performance, LSE.

Mansfield, E., Teece, D., and Romeo, A. (1979). "Overseas research and development by US-based firms". Economica, 46(182):187-96.

Mayer, T., Melitz, M. J., and Ottaviano, G. I. P. (2012). "Market size, competition, and the product mix of exporters". CEP Discussion Papers dp1146, Centre for Economic Performance, LSE.

Melitz, M. J. (2003). "The impact of trade on intra-industry reallocations and aggregate industry productivity". Econometrica, 71(6):1695-1725. 
Melitz, M. J. and Ottaviano, G. I. P. (2008). "Market size, trade, and productivity". The Review of Economic Studies, 75(1):295-316.

Naghavi, A. and Comune, M. (2012). "The globalisation of innovation: Challenges and opportunities for Europe". Review of Environment, Energy and Economics - Re3.

Nelson, R. R. (1959). "The simple economics of basic scientific research". Journal of Political Economy, 67:297.

Nocke, V. and Yeaple, S. R. (2012). "Globalization and multiproduct firms". CEPR Discussion Papers 9037, C.E.P.R. Discussion Papers.

Noteboom, B. (2000). Learning and Innovation in Organizations and Economies. Oxford University Press.

Papke, L. E. and Wooldridge, J. M. (1996). "Econometric methods for fractional response variables with an application to 401 (K) plan participation rates". Journal of Applied Econometrics, 11(6):619-632.

Papke, L. E. and Wooldridge, J. M. (2008). "Panel data methods for fractional response variables with an application to test pass rates". Journal of Econometrics, 145(1):121-133.

Rosell, C. and Liu, R. (2012). "Import competition, multi-product firms, and basic innovation". Mimeo.

Trajtenberg, M., Henderson, R., and Jaffe, A. (1997). "University versus corporate patents: A window on the basicness of invention". Economics of Innovation and New Technology, 5(1):19-50.

Van de Ven, W. P. M. M. and van Praag, B. M. (1981). "The demand for deductibles in private health insurance: A probit model with sample selection". Journal of Econometrics, 17(2):229-252. 


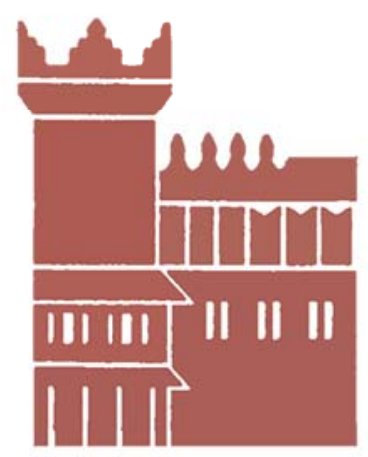

Alma Mater Studiorum - Università di Bologna DEPARTMENT OF ECONOMICS

Strada Maggiore 45

40125 Bologna - Italy

Tel. +39051 2092604

Fax +390512092664

http://www.dse.unibo.it 